IZA DP No. 4384

Subsidizing Firm Entry in Open Economies

Michael Pflüger

J ens Südekum

August 2009 


\title{
Subsidizing Firm Entry in Open Economies
}

\author{
Michael Pflüger \\ University of Passau, \\ DIW Berlin and IZA \\ Jens Südekum \\ University of Duisburg-Essen, \\ Ruhr Graduate School of Economics and IZA
}

\section{Discussion Paper No. 4384 \\ August 2009}

\author{
IZA \\ P.O. Box 7240 \\ 53072 Bonn \\ Germany \\ Phone: +49-228-3894-0 \\ Fax: +49-228-3894-180 \\ E-mail: iza@iza.org
}

Any opinions expressed here are those of the author(s) and not those of IZA. Research published in this series may include views on policy, but the institute itself takes no institutional policy positions.

The Institute for the Study of Labor (IZA) in Bonn is a local and virtual international research center and a place of communication between science, politics and business. IZA is an independent nonprofit organization supported by Deutsche Post Foundation. The center is associated with the University of Bonn and offers a stimulating research environment through its international network, workshops and conferences, data service, project support, research visits and doctoral program. IZA engages in (i) original and internationally competitive research in all fields of labor economics, (ii) development of policy concepts, and (iii) dissemination of research results and concepts to the interested public.

IZA Discussion Papers often represent preliminary work and are circulated to encourage discussion. Citation of such a paper should account for its provisional character. A revised version may be available directly from the author. 
IZA Discussion Paper No. 4384

August 2009

\section{ABSTRACT}

\section{Subsidizing Firm Entry in Open Economies}

Entrepreneurs who decide to enter an industry are faced with different levels of effective entry costs in different countries. These costs are heavily influenced by economic policy. What is not well understood is how international trade affects the government incentive to impact on entry costs, and how entry subsidies can be used strategically in open economies. We present a general equilibrium model of monopolistic competition with two (potentially) asymmetric countries and heterogeneous firms where government subsidizes entry of domestic entrepreneurs. Under autarky the entry subsidy indirectly corrects for the monopoly pricing distortion. In the autarky equilibrium these subsidies trigger entry, but they eventually do not lead to more but to better firms in the market. In the open economy there is another, strategic motive for entry subsidies as the tightening of domestic market selection also affects exporting decisions for domestic and foreign firms. Our analysis shows that entry subsidies in the Nash-equilibrium are first increasing, then decreasing in the level of trade openness. This implies a U-shaped relationship between openness and effective entry costs. Merging crosscountry data on entry costs with international trade openness indices we empirically confirm this theoretical prediction.

JEL Classification: F12, F13, H25, L11

Keywords: firm entry, subsidies, heterogeneous firms, international trade, monopolistic competition, entry regulation, strategic trade policy

Corresponding author:

Jens Südekum

University of Duisburg-Essen

Mercator School of Management

Lotharstrasse 65

47057 Duisburg

Germany

Email: jens.suedekum@uni-due.de 


\section{Introduction}

An entrepreneur who decides to enter an industry must undergo a number of legal procedures in order to start up a firm. The complexity of this process of obtaining all necessary permits and complying with all other relevant official requests differs vastly across countries. In a seminal study, Djankov et al. (2002) have collected data on entry regulation in 85 different countries for the year 1999 and convert these figures into pecuniary and time costs of firm entry. They report that starting a business in Canada requires only two official procedures and works almost instantaneously, while setting up a firm in the Dominican Republic is much more complicated and requires some 21 different procedures and a waiting time of at least 80 business days. At the same time, governments also often encourage firm entry by means of start-up grants, guaranteed loans, preferential tax treatments, or other forms of subsidies. Entrepreneurs are thus faced with different levels of effective entry costs in different countries. These costs, which are typically sunk for the entrants, are not entirely set by governments as they also include upfront expenses for research and development, market search etc., but they are heavily influenced by economic policy.

In principle there are various reasons why governments may regulate entry. Legal barriers may be due to benevolent motives, such as the attempt to ensure that sellers meet some minimum quality standards in order to supply desirable goods to consumers, but also to the self-interest of bureaucrats who trade entry permits for lobbying contributions (see Djankov et al. 2002 for a detailed discussion). Subsidies that encourage entry are typically paid out of the motive to increase competition in an industry and to restrain market power of incumbent firms to the benefit of consumers (Bresnahan and Weiss 1991). As these subsidies are, by definition, only paid to new firms there is a great deal of uncertainty involved in this public policy. It is well known that only a small share of firms that enter an industry survives the first few years of operation (Geroski 1995), hence some upfront government support will go to failing businesses that never succeed in the market. This uncertainty is one reason why public subsidies in support of new firm foundation are typically regarded to be only an imperfect policy option to target market imperfections (Reitzes and Grawe 1999), yet one that is among the most widespread and frequently used instruments of industrial policy in practice (Santarelli and Vivarelli 2002).

What is not well understood in the literature is how international trade affects the government incentive to impact on effective entry costs for domestic entrepreneurs, and how entry subsidies can be used strategically in open economies. These are the questions that we explore in this paper. We build on an extended version of the model of intra-industry trade with heterogeneous firms by Melitz (2003), where we assume two (potentially asymmetric) 
countries and two sectors: a monopolistically competitive manufacturing industry and a perfectly competitive outside sector. That model is well suited as the basis for our analysis, because it explicates the process of firm entry with ex-ante uncertainty in a general equilibrium framework. Entrepreneurs in the manufacturing sector pay a sunk entry cost and randomly draw their productivity level. Only firms with a sufficiently high draw that exceeds some endogenously determined cutoff level remain in the market. Firms with too low productivity immediately exit. When the economy opens up to trade only the most productive firms self-select into export markets and gain market shares. Relatively less productive firms sell only domestically, and the least efficient producers are forced to exit.

The level of sunk entry costs, which is crucial for the analysis, is purely exogenous in Melitz (2003) and in the subsequent vast literature on firm heterogeneity. In this paper we introduce a government that pays subsidies to reduce effective entry costs for domestic entrepreneurs. We show that under autarky a welfare-maximizing government would in fact choose a strictly positive entry subsidy that is financed through lump-sum taxes. Such a policy targets the pricing distortion due to imperfect competition in the manufacturing industry. It does so only imperfectly, however. If the government could directly subsidize manufacturing consumption, it would choose this more direct way of targeting market imperfections. Yet, unlike entry subsidies, we rarely observe direct consumption subsidies in practice. The observation that real-world policies often deviate from first-best policy schemes is quite common and usually seen as the result of political economy mechanisms (see, e.g., Corden 1997), which are beyond the scope of this paper. Hence our focus in this paper is on a highly pervasive, though imperfect policy instrument. Turning to the effects of the entry subsidy, we show that they naturally increase the mass of entrepreneurs who decide to start a business. Yet, the mass of surviving firms is unaffected in the autarky equilibrium and the subsidies only impacts on the toughness of selection, the cutoff productivity. In other words, the entry subsidy does not lead to more but to better firms in general equilibrium.

In the open economy, domestic subsidies tighten domestic firm selection and thereby make export market entry more difficult for foreign firms. This negatively affects expected profits and the quality of foreign firms, ceteris paribus, because they anticipate the stiffer competition with more productive domestic rivals ex-ante. Due to these general equilibrium interactions, there is scope for governments to use entry subsidies strategically in order to grasp a competitive advantage in trade. This strategic use is particularly interesting, because entry subsidies to local entrepreneurs are mainly perceived as a domestic policy and not as a classical trade policy instrument (such as import tariffs or export subsidies) whose abuse is put under scrutiny by international organizations like the WTO. In the analysis we solve for the entry subsidies in the Nash-equilibrium, which turn out to depend on the level of trade 
openness. More specifically, we find that gradual trade liberalization first leads to an increase, then to a decrease of entry subsidies. Put differently, our model predicts a U-shaped relationship between trade openness and the level of effective entry costs.

This prediction is then briefly tested empirically by merging the entry cost data by Djankov et al. (2002) with international trade openness indices. This simple empirical analysis confirms our main theoretical result. According to our estimates most countries are actually located on the downward-sloping range of the U-shape. This suggests that most countries may actually increase their efforts to engage in strategic entry subsidization in the future, when they are exposed to a trend of further trade integration.

This paper is structured as follows. In the rest of this section we review some related literature. Section 2 analyzes the closed economy case. In section 3 we turn to the open economy, and in section 4 we analyze entry subsidies for the case of two symmetrical (equally large and technologically advanced) countries. Section 5 deals with the case of two asymmetric countries. The empirical analysis is presented in section 6. Section 7 concludes.

\subsection{Related literature}

Our paper is firstly related to the general literature on firm entry in industrial organization. The contribution by Hopenhayn (1992) is particularly noteworthy here, because that model also explicitly features ex-ante uncertainty of entrants about their productivity level in a general equilibrium setting. It also discusses the comparative statics of the model with respect to sunk entry costs, yet without analyzing endogenous government subsidies to entry. Furthermore, our paper is mainly differentiated from that literature because we explicitly deal with open economy issues and study the effects of gradual trade liberalization.

Secondly, our paper is related to the large literature on strategic trade policy (see Brander 1995 for a survey), which has studied government interactions in open economies. Our paper differs in two main respects. Firstly, while this literature has extensively studied some policy instruments (such as export or import subsidies, state aid, tariffs, quotas, etc.) it has remained largely silent on entry regulation, with the paper by Reitzes and Grawe (1999) being one exception. Secondly, this literature typically assumes oligopolistic market structures and does not focus on the general equilibrium effects of trade. In the older literature on trade with monopolistic competition and homogeneous firms there is also an extensive discussion on the under-consumption of varieties and the scope for corrective policies (see Helpman and Krugman 1985, Flam and Helpman 1987). Our paper differs from that literature because we introduce Melitz-type firm heterogeneity. This gives rise to several new insights, for example that entry subsidies may not mainly increase the mass but the average productivity of firms. 
Thirdly, a recent literature has started to analyze policy issues in the now standard heterogeneous firms frameworks by Melitz (2003) and Melitz and Ottaviano (2008). Demidova and Rodriguez-Clare (2009) conduct a welfare analysis of a small open economy and study various policy instruments that can be used to improve the allocation. They do not address government subsidies to entry costs, however, and they do not analyze a strategic interaction of governments in the setting of a domestic policy like the present paper does. Baldwin and Forslid (2006) also present a welfare analysis of a one-sector Melitz-type model. Jorgensen and Schröder (2008) study the effects of exogenous tariffs, and Cole (2008) considers optimal tariffs when firms differ in fixed rather than in variable costs. In Cole (2008) firms can also choose to engage in FDI rather than in exporting. None of these papers discusses endogenous entry regulation. Chor (2009) analyzes the case where governments subsidize the fixed export costs for foreign firms, but he does not consider subsidies to the effective entry costs of domestic entrepreneurs. Though he identifies a similar pro-selective effect of subsidies, he does not consider a strategic policy game of governments.

Finally, this paper is also broadly related to the literature on international tax competition. However, in our framework governments set taxes only in order to finance subsidies for domestic entrants. They do not engage in a race to attract mobile firms, which is the typical setup of tax competition models. In that literature, Davies and Eckel (2009), Baldwin and Okoubo (2009) and Krautheim and Schmidt-Eisenlohr (2009) have considered heterogeneous firms, but again none of these papers considers the strategic use of entry regulation.

\section{Closed economy}

We first consider the case of a single country under autarky. Labour is the only factor of production, and there are $L$ workers who supply one unit of labour each. There are two industries, $A$ and $C$. The homogeneous good $A$ is characterized by constant returns to scale and perfect competition. The sector $C$ is the monopolistically competitive manufacturing industry consisting of a continuum of differentiated varieties. Each variety is produced by a single firm under increasing returns, and firms are heterogeneous in their productivity.

\subsection{Preferences}

Preferences for household $h$ are defined over the homogenous commodity $A$ and the set of differentiated varieties $(\Omega)$ according to the following quasi-linear, logarithmic utility function with CES sub-utility:

$$
U^{h}=\beta \ln C^{h}+A^{h} \quad C^{h}=\left(\int_{z \in \Omega} q^{h}(z)^{\rho} d z\right)^{1 / \rho},
$$


where $q^{h}(z)$ denotes household $h$ 's consumption of variety $z$ and where $0<\rho<1, \beta>0$. The elasticity of substitution between any two varieties is given by $\sigma \equiv 1 /(1-\rho)>1$. As is well known from Dixit and Stiglitz (1977), the variable $C^{h}$ can be understood as the consumption of the manufacturing aggregate with aggregate price

$$
P=\left(\int_{z \in \Omega} p(z)^{1-\sigma} d z\right)^{1 /(1-\sigma)} .
$$

The budget constraint of an individual is $P \cdot C^{h}+A^{h}=y^{h}$, where $y^{h}$ denotes income. From standard utility maximization it follows that per-capita expenditure on the manufacturing aggregate and the numeraire good are given by $P \cdot C^{h}=\beta$ and $A^{h}=y^{h}-\beta$, respectively, and that indirect utility is of the form $V=y-\beta \ln P+\beta(\ln \beta-1)$ where we drop the index $h$ from now on as households are identical. ${ }^{1}$ It must be ensured that $\beta<y$, i.e., the preference for varieties relative to the outside commodity must be sufficiently small. Total demand for a single variety $z$ is denoted by $q(z)=\beta L \cdot p(z)^{-\sigma} \cdot P^{\sigma-1}$, and total revenue for that variety is $r(z)=p(z) \cdot q(z)=\beta L \cdot(P / p(z))^{\sigma-1}$. Finally, overall manufacturing expenditure equals $\beta L$.

\subsection{Production and firm behaviour}

Firms in the $A$-sector transform one unit of labour into one unit of output. This pins down the wage in the closed economy, which is equal to one. Technology in the manufacturing sector is such that, to produce $q$ units of output, a firm needs $\ell=f+q / \varphi$ units of labour. The fixed overhead production cost $f$ is the same, but the variable labour requirements $(1 / \varphi)$ differ across firms. Due to the CES preferences for manufacturing varieties, each firm faces a residual demand curve with constant price elasticity $-\sigma$ (regardless of $\varphi$ ). This implies that all firms charge prices which are constant mark-ups over the firm-specific level of marginal costs. Specifically, a firm with marginal cost $(1 / \varphi)$ charges the price

$$
p(\varphi)=\frac{\sigma}{(\sigma-1) \varphi}=\frac{1}{\rho \cdot \varphi}
$$

Revenue and profits of that firm are then, respectively, given by $r(\varphi)=\beta L \cdot(\rho \varphi P)^{\sigma-1}$ and $\pi(\varphi)=r(\varphi) / \sigma-f$. It can be seen that a firm with higher productivity level $\varphi$ charges a lower price, sells a larger quantity and has higher revenue and profits. Furthermore, as all firm-specific variables differ only with respect to $\varphi$, the CES price index (2) can be rewritten in the following form (see Melitz 2003):

\footnotetext{
${ }^{1}$ Note that the quasi-linear preferences eliminate income effects of demand for manufacturing varieties and imply constant marginal utility of income. Upon request we provide a proof that all key results of this paper also hold with Cobb-Douglas upper tier preferences.
} 


$$
P=M^{1 /(1-\sigma)} \cdot p(\tilde{\varphi})=M^{1 /(1-\sigma)} \cdot \frac{1}{\rho \tilde{\varphi}}, \quad \text { with } \tilde{\varphi} \equiv\left[\int_{0}^{\infty} \varphi^{\sigma-1} \cdot \mu(\varphi) d \varphi\right]^{1 /(\sigma-1)} .
$$

$M$ denotes the mass of manufacturing firms/varieties in the market, $\mu(\varphi)$ describes the productivity distribution across these active firms (which has positive support over a subset of $(0, \infty))$, and $\tilde{\varphi}$ can be understood as the average productivity level.

\subsection{Entry and exit}

There exists a mass of potential entrepreneurs who can enter the manufacturing industry subject to an effective sunk entry cost $\tilde{f}_{e}$. At each point in time there are $M^{E}$ such entrepreneurs. Upon entry they learn about their productivity level $\varphi$, which is drawn from a common and known distribution function $g(\varphi)$ with support $(0, \infty)$ and cumulative density function $G(\varphi)$. After the productivity level is revealed an entrant can decide to exit immediately or to remain active in the market, in which case that firm earns constant perperiod profits $\pi(\varphi)$. It will exit at once if $\pi(\varphi)<0 \leftrightarrow r(\varphi)<\sigma f$. Only those firms remain active whose productivity draw exceeds some cutoff level $\varphi^{*}>0$. Every surviving firm may then be hit by a bad shock which forces it to shut down. This event occurs with probability $\delta>0$ at every point in time and is independent of $\varphi$ (see Melitz 2003 for a discussion of this assumption). In a stationary equilibrium without time discounting, on which we focus in this paper, the mass of entrants which make it into the market equals the mass of firms that are forced to shut down. Formally, $p_{i n} \cdot M^{E}=\delta \cdot M$, where $p_{i n}=1-G\left(\varphi^{*}\right)$ is the survival probability. The endogenous productivity distribution among surviving firms, $\mu(\varphi)$, is then the conditional (left-truncated) ex-ante distribution $g(\varphi)$ on the domain $\left[\varphi^{*}, \infty\right)$.

\subsection{Government and entry subsidization}

The novel focus of this paper is the role of governments in influencing sunk entry costs. We assume that effective entry costs are $\tilde{f}_{e}=f_{e}-s$ where $f_{e}$ denotes some exogenous raw cost capturing unavoidable irreversible investments for research and development. Governments can reduce the effective sunk costs for entering firms. In practise, this can partly be achieved by simplifying legal procedures, reducing red tape or adopting related types of deregulation. Such reforms may reduce bureaucratic rents (which are not the focus of this paper) but do not impose the need for collecting taxes. In this paper we shall focus on actual entry subsidies (e.g., for start-up grants) that need to be financed by the government. Specifically, we assume that it levies a lump-sum tax $t$. As gross per-capita income is equal to one by the choice of the numeraire, individual after-tax income is $y=1-t$ and aggregate tax revenue is $t L$. This money is spent on the non-refundable entry subsidy $s$ that is unconditionally available to all 
entrants $M^{E}$ before productivity $\varphi$ is drawn, and that does not have to be paid back by the entrepreneurs if they succeed in the market. ${ }^{2}$ The government budget constraint is therefore given by $t L=s \cdot M^{E}(s)$ where the mass of entrants depends on the entry subsidy $s$.

\subsection{Equilibrium in the closed economy and parameterization}

To derive the equilibrium within the manufacturing sector we draw on Melitz (2003) who has shown that equilibrium under autarky can be characterized by two conditions, the free entry condition (FEC) and the zero cutoff profit condition (ZCPC).

$$
\text { (FEC) } \bar{\pi}=\frac{\delta \tilde{f}_{e}}{1-G\left(\varphi^{*}\right)} \quad \text { (ZCPC) } \bar{\pi}=f\left[\left(\frac{\tilde{\varphi}}{\varphi^{*}}\right)^{\sigma-1}-1\right]
$$

$\bar{\pi}=\pi(\tilde{\varphi}, P(\tilde{\varphi}), \cdot)$ is the ex-ante expected profit, which is equivalent to the profit level of the average surviving firm (with productivity level $\tilde{\varphi}$ ). FEC states that entry occurs until the value of entry, $v^{E}=E\left[\sum_{t=0}^{\infty}(1-\delta)^{t} \cdot \pi(\varphi)\right]-\tilde{f}_{e}$, is driven to zero. ZCPC states that the cutoff firm generates revenue $r\left(\varphi^{*}\right)=\sigma f$, which, by using $r(\tilde{\varphi}) / r\left(\varphi^{*}\right)=\left(\tilde{\varphi} / \varphi^{*}\right)^{\sigma-1}$ and $\bar{\pi}=r(\tilde{\varphi}) / \sigma-f$, implies the expression above. Melitz proves that (FEC) and (ZCPC) imply a unique solution for $\bar{\pi}$ and $\varphi^{*}$ for a wide range of distribution functions $g(\varphi)$ that only have to satisfy some mild conditions. Once the equilibrium values of $\bar{\pi}$ and $\varphi^{*}$ are obtained, the equilibrium mass of entrants $M^{E}$ and of surviving firms $M$ can be derived as follows.

The consumers' budget constraints imply that aggregate consumption expenditure for varieties $\beta L$ must equal the aggregate revenue of the surviving firms, $R=M \cdot \bar{r}$, where the average revenue of surviving firms is given by $\bar{r}=r(\widetilde{\varphi})=\sigma(\vec{\pi}+f)$. Moreover, market clearing in the $A$-sector commands that the value of consumption equals the value of production, $(1-t-\beta) L=(1-\gamma) L$, where $\gamma$ denotes the share of the workforce that is employed in manufacturing. Hence, $\gamma=\beta+t$, in our model. Combining these results it follows that $M=\beta L / \sigma(\bar{\pi}+f)=(\gamma-t) L / \sigma(\bar{\pi}+f)$ and $M^{E}=\delta M /\left(1-G\left(\varphi^{*}\right)\right)$.

In order to obtain more specific results, we assume that firms draw their productivities from a Pareto-distribution, such that $G(\varphi)=1-\left(\varphi^{\min } / \varphi\right)^{k}$ and $g(\varphi)=k\left(\varphi^{\min }\right)^{k} \cdot \varphi^{-k-1}$, where $\varphi^{\min }>0$ is the lower bound for productivity draws and $k$ is the shape parameter. ${ }^{3}$ Using this parameterization in (4), and assuming $k>\sigma+1$, we find that average productivity is proportional to the cutoff productivity, $\tilde{\varphi}=\left(\frac{k}{k+1-\sigma}\right)^{1 /(\sigma-1)} \varphi^{*}>\varphi^{*}$. Furthermore, (FEC) and (ZCPC) are then given by $\bar{\pi}=\delta \tilde{f}_{e}\left(\varphi^{\min }\right)^{-k}\left(\varphi^{*}\right)^{k}$ and $\bar{\pi}=(f(\sigma-1)) /(k+1-\sigma)$,

\footnotetext{
${ }^{2}$ It can be shown that a welfare-maximizing government would not run a program where entry subsidies are financed through profit taxes for surviving firms. This is intuitive as profit taxes (conditional on survival) are anticipated by entrepreneurs and reduce the value of entry, which offsets the intention for entry subsidies.

${ }^{3}$ The Pareto distribution has been extensively used in the previous literature on heterogeneous firms (see Bernard et al., 2007; Helpman et al., 2008; Melitz and Ottaviano, 2008; Behrens et al. 2009).
} 
respectively, which imply the following closed form solutions for the cutoff, mass of entrants, and mass of surviving firms under autarky (indicated with subscript “aut”):

$$
\varphi_{\text {aut }}^{*}=\left(\frac{f(\sigma-1)\left(\varphi^{\min }\right)^{k}}{\delta(k+1-\sigma) \tilde{f}_{e}}\right)^{1 / k}, \quad M_{\text {aut }}^{E}=\left(\frac{\sigma-1}{\sigma k \tilde{f}_{e}}\right) \cdot \beta L, \quad M_{\text {aut }}=\left(\frac{k+1-\sigma}{\sigma k f}\right) \cdot \beta L
$$

Note that $M=\beta L / \bar{r}(\tilde{\varphi})$ and $\bar{r}(\tilde{\varphi})=\left(\tilde{\varphi} / \varphi^{*}\right)^{\sigma-1} \cdot \sigma f$ also imply $M=(\beta L / \sigma f)\left(\tilde{\varphi} / \varphi^{*}\right)^{1-\sigma}$. Using this in (4), and recalling that indirect utility is given by $V=y-\beta \ln P+\beta(\ln \beta-1)$, we obtain the following expression for indirect utility under autarky

$$
V_{\text {aut }}=y-\beta \cdot \ln \left[\left(\frac{\beta L}{\sigma f}\right)^{\frac{1}{1-\sigma}} \cdot \frac{1}{\rho \cdot \varphi_{\text {aut }}^{*}}\right]+\beta(\ln \beta-1)
$$

Hence, countries with higher labour endowment $L$ and/or higher cutoff $\varphi_{\text {aut }}^{*}$ are better off.

\subsection{Endogenous policy determination in the closed economy}

Using (5) the government budget constraints commands that

$$
t \cdot L=s \cdot M_{\text {aut }}^{E}(s)=s \cdot\left(\frac{\sigma-1}{\sigma k\left(f_{e}-s\right)}\right) \cdot \beta L \rightarrow s=\frac{\sigma k t}{\beta(\sigma-1)+\sigma k t} \cdot f_{e}
$$

Eq. (7) implies that the subsidy which satisfies the government budget constraint is increasing and concave in the tax rate: $s$ can only rise under-proportionally when taxes $t$ are increased, as higher subsidies trigger further entry and thus reduce the subsidy per entrant. Furthermore, $s<f_{e}$ always holds, hence subsidies do not cover the entire raw sunk costs of the entrepreneurs. The government in the closed economy chooses the subsidy $s$ so as to maximize total welfare $W_{\text {aut }}=L \cdot V_{\text {aut }}$. Using (5) and the relationship between the subsidy and the lump-sum tax implied by (7), the maximization problem can be formulated as:

$$
\operatorname{Max}_{\{t\}} W_{\text {aut }}=L\left[1-t+\beta \cdot \ln \varphi_{\text {aut }}^{*}(s(t))+\frac{\beta}{\sigma-1} \cdot \ln L+b\right],
$$

where $b \equiv \beta(\ln (\beta / \rho)-1)+\frac{\beta}{\sigma-1} \cdot \ln (\beta / \sigma f)$ is a constant. This problem gives rise to the following first order condition for a welfare maximum

$$
\beta \cdot \hat{\varphi}_{\text {aut }}^{*}=1, \quad \text { where } \hat{\varphi}_{\text {aut }}^{*}=\frac{d \ln \varphi_{\text {aut }}^{*}}{d t}=\frac{1}{\varphi_{\text {aut }}^{*}} \cdot \frac{d \varphi_{\text {aut }}^{*}}{d s} \cdot \frac{d s}{d t}
$$

Recall that marginal costs of taxation are constant and equal to one in our model. Condition (8) states that the optimal tax rate is set such that the marginal benefit of the last tax- $€$, in terms of the cutoff increase that it can generate by subsidizing entry, is also just equal to one. Hence, we can state: 
Proposition 1 Consider a government that subsidizes entry costs and finances the expenses through lump-sum taxes. Under autarky government sets the following entry subsidy and tax:

$$
s_{\text {aut }}^{*}=\frac{f_{e}}{\sigma} \quad t_{\text {aut }}^{*}=\frac{\beta}{\sigma k}
$$

Proof: $\quad \varphi_{\text {aut }}^{*}=\left(\frac{f(\sigma-1)\left(\varphi^{\min }\right)^{k}}{\delta(k+1-\sigma)\left(f_{e}-s\right)}\right)^{1 / k} \quad$ from $\quad$ (5) implies $\quad \frac{1}{\varphi_{\text {aut }}^{*}} \cdot \frac{d \varphi_{\text {aut }}^{*}}{d s}=\frac{1}{k\left(f_{e}-s\right)}$. From (7) we obtain $\frac{d s}{d t}=\frac{\beta \sigma k(\sigma-1)}{(\beta(\sigma-1)+\sigma k t)^{2}} \cdot f_{e}$, hence $\quad \hat{\varphi}_{\text {aut }}^{*}=\frac{\sigma}{\beta(\sigma-1)+\sigma k t}$. Solving $\beta \cdot \hat{\varphi}_{\text {aut }}^{*}=1$ yields the optimal tax $t_{\text {aut }}^{*}$, which we substitute into (7) to obtain $s_{\text {aut }}^{*}$.

An inspection of the subsidy-tax scheme yields several important insights: The government indeed has an incentive to subsidize entry as long as $\beta>0$. The optimal subsidy (and, hence, also the optimal tax) is inversely related to the elasticity of substitution, $\sigma$. Moreover, the optimal subsidy increases with size of the (unavoidable) raw entry cost, $f_{e}$. Due to the selection process that is operative in this model, this dependency gets mirrored in the negative dependency of the optimal tax on the shape parameter $k$. The intuition of these results is straightforward: the incentive to subsidize arises from the distortion induced by mark-up pricing in the manufacturing sector. The incentive to subsidize is, thus, positively related to the discrepancy between price and marginal cost, $1 / \sigma$. The positive dependency of the subsidy on $f_{e}$ (and the negative dependency of the tax on $k$ ) reflects the fact that entry subsidies are not the direct way to address the monopoly distortion. Rather, they indirectly target the distortion through the process of market entry.

Before looking at this process in more detail, it is important to explore the optimal policy when the government disposes a full set of instruments. Suppose that government additionally has a consumption subsidy available. We can then show:

Proposition 2 Consider a government that simultaneously disposes a lump-sum tax and two subsidy instruments, a consumption subsidy and an entry subsidy. Under autarky this government would choose a consumption subsidy $s_{c}=1 / \sigma$ but no entry subsidy, $s=0$, and set the lump-sum tax $t=\beta /(\sigma-1)$. This policy-scheme achieves the first-best allocation.

Proof: We provide the technical derivation of this subsidy-tax scheme in appendix A. To prove that the allocation is then indeed first-best we refer to the fact that the static monopoly distortion is the only (net) distortion in our Dixit-Stiglitz model. ${ }^{4}$

\footnotetext{
${ }^{4}$ It is well-established that the Dixit-Stiglitz-model in addition exhibits a consumer surplus effect (an entering firm does not consider the extra consumer surplus it generates) and a profit destruction effect (an entering firm
} 
Proposition 2 thus tells us that a government would abstain from using a market entry subsidy if it had a full set of instruments available. As we have documented in our introduction the use of entry subsidies is highly pervasive in practise, however, whereas the first-best instrument of consumption subsidies are hardly used. We therefore believe that it is important to trace the effects of this relevant instrument of entry subsidies in this paper.

This can be done by using eqs. (5) and (6). It is straightforward to see that the mass of entrants $\left(M_{\text {aut }}^{E}\right)$ is higher with the entry subsidy $\left\{t=t_{\text {aut }}^{*}, s=s_{\text {aut }}^{*}\right\}$ than without it $\{t=s=0\}$. In principle, restoring the stationary equilibrium condition, $p_{i n} \cdot M^{E}=\delta \cdot M$, requires either a decrease of the survival probability $p_{i n}$, or an increase in the mass of firms in the market (which would imply higher firm turnover and lower average profits $\bar{\pi}$ ), or a combination of the two. It turns out that, with the Pareto-parameterization, the mass of active manufacturing firms $M_{\text {aut }}$ (and thus consumption variety) remains constant in the steady-state. The surviving firms become more productive on average ( $\varphi_{\text {aut }}^{*}$ and $\tilde{\varphi}_{\text {aut }}$ increase), however. In other words, the entry subsidy does not lead to more but to better firms in the market by tightening selection. This higher average productivity implies that the aggregate physical output of manufacturing firms increases and that the CES price index $P_{\text {aut }}$ decreases. Consumption of manufacturing good is higher with $\left\{t=t_{\text {aut }}^{*}, s=s_{\text {aut }}^{*}\right\}$ than with $\{t=s=0\}$ because the better manufacturing firms produce and sell more output at lower prices.

\section{The open economy}

We now explore the effects of market entry subsidies in an open economy setting with two countries $i=H, F$ which may differ in population size $L_{i}$ and technology. Regarding technology, we assume that entrants in country $i$ draw from a country-specific Paretodistribution with common shape parameter $k$ but potentially different lower bounds, $\varphi_{i}^{\min } .^{5}$ Firms in the two countries may face different effective sunk entry costs $\tilde{f}_{e, i}=f_{e}-s_{i}$ which are due to differences in the subsidy-tax schemes implemented by their respective governments. We shall ultimately be interested in the endogenous determination of these policy schemes where governments are assumed to maximize the welfare of their own citizens. We study these non-cooperative equilibria with symmetric and asymmetric countries in sections 4 and

does not consider the impact it has on profits of existing varieties) in addition to the classic monopoly distortion. However, these two additional distortions exactly offset each other, as Grossman and Helpman (1991, Appendix A 3.3) have shown in the context of a growth model. Baldwin (2005) has adapted this proof to the Melitz-model. An insightful discussion of the distortions in the Melitz-model from the perspective of a small open economy is provided by Demidova and Rodriguez-Clare (2009).

${ }^{5}$ Note that if $H$ and $F$ are identical in all respects, except for $\varphi_{H}^{\min }>\varphi_{F}^{\min }$, there is a first-order stochastic dominance of the productivity distribution in $H$, which would be the technologically leading country in the definition of Demidova (2008). We therefore say that country $H$ has a "better technology" if $\varphi_{H}^{\min }>\varphi_{F}^{\min }$. 
5 , respectively. In this section we start out to analyze the international equilibrium under the assumption that the policy parameters $\left\{t_{H}, s_{H}, t_{F}, s_{F}\right\}$ are exogenous.

There are both fixed and variable trade costs in the manufacturing sector. First, if a firm from country $i$ decides (after learning its $\varphi$ ) to become an exporter and to sell to country $j$ it must pay an additional fixed cost $f_{x}$ on top of the fixed cost $f$ that accrues irrespective of export status. Second, for one unit of output to arrive in $j$ the firm in $i$ must ship $\tau>1$ units, where $\tau$ denotes the variable iceberg trade costs. Trade in the numeraire sector $A_{i}$ is costless, which ensures factor price equalization (FPE) provided both countries produce both types of goods.

\subsection{Domestic and export cutoffs}

If a firm from country $j$ sells to country $i$, its exporting profits are $\pi_{x j}(\varphi)=r_{x j}(\varphi) / \sigma-f_{x}$. Clearly, there is a threshold level $\varphi_{x j}^{*}$ such that this firm just breaks even abroad, i.e. $r_{x j}\left(\varphi_{x j}^{*}\right)=r_{i}\left(\varphi_{x j}^{*} / \tau\right)=\sigma f_{x}$. Similarly, for the domestic cutoff firm which just breaks even in its local market, we have $r_{i}\left(\varphi_{i}^{*}\right)=\sigma f$. Since $r_{i}(\varphi)=\left(\rho \varphi P_{i}\right)^{\sigma-1} \beta L_{i}$ the following link between domestic and export cutoffs exists: $\varphi_{x j}^{*}=\Lambda \cdot \varphi_{i}^{*}$ where $\Lambda \equiv\left[\tau \cdot\left(f_{x} / f\right)^{1 /(\sigma-1)}\right]$. Throughout this paper we shall assume $f_{x} \geq f$ which is a sufficient condition to ensure that $\Lambda>1$. To solve for the domestic cutoffs $\varphi_{H}^{*}$ and $\varphi_{F}^{*}$ (which inter alia pin down the export cutoffs) we again make use of the (FEC) and the (ZCPC). ${ }^{6}$ The (FEC) remains unchanged compared to the autarky case, and reads as follows for country $i$ :

$$
\left[1-G_{i}\left(\varphi_{i}^{*}\right)\right] \frac{\bar{\pi}_{i}}{\delta}=f_{e}-s_{i} \Leftrightarrow \quad \bar{\pi}_{i}=\delta\left(f_{e}-s_{i}\right)\left(\varphi_{i}^{\min }\right)^{-k}\left(\varphi_{i}^{*}\right)^{k}
$$

As for the (ZCPC), ex-ante expected profits are now given by $\bar{\pi}_{i}=\pi_{i}\left(\tilde{\varphi}_{i}\right)+p_{x i} \cdot \pi_{x i}\left(\tilde{\varphi}_{x i}\right)$ where $\tilde{\varphi}_{i}$ and $\tilde{\varphi}_{x i}$ are the average productivities among all active and, respectively, among the exporting firms from $i$. The exporting probability conditional on survival is given by $p_{x i}=\left(\varphi_{i}^{*} / \varphi_{x i}^{*}\right)^{k}=\left(\varphi_{i}^{*} / \Lambda \varphi_{j}^{*}\right)^{k}$. Using this together with $\tilde{\varphi}_{i} / \varphi_{i}^{*}=\tilde{\varphi}_{x i} / \varphi_{x i}^{*}=\left(\frac{k}{k+1-\sigma}\right)^{1 /(\sigma-1)}$ we can write the (ZCPC) as follows:

$(\mathrm{ZCPC}) \quad \bar{\pi}_{i}=f \cdot\left(\left(\frac{\tilde{\varphi}_{i}}{\varphi_{i}^{*}}\right)^{\sigma-1}-1\right)+p_{x i} \cdot f_{x} \cdot\left(\left(\frac{\tilde{\varphi}_{x i}}{\varphi_{x i}^{*}}\right)^{\sigma-1}-1\right) \Leftrightarrow \quad \bar{\pi}_{i}=\frac{f(\sigma-1)}{k+1-\sigma} \cdot\left[1+\phi\left(\frac{\varphi_{i}^{*}}{\varphi_{j}^{*}}\right)^{k}\right]$, where $\phi \equiv \tau^{-k} \cdot\left(f / f_{x}\right)^{\frac{k+1-\sigma}{\sigma-1}}$ can be understood as a measure of trade freeness which is higher, the lower the variable or fixed trade costs are. Note that $0<\phi<1$ due to $f_{x}>f$.

\footnotetext{
${ }^{6}$ See Demidova (2008) for a lucid exposition of the cutoff determination with asymmetric countries, where (FEC) and (ZCPC) are interdependent. Compared to that paper we consider further asymmetries across countries (size and effective entry costs) but work with a specific functional form for the productivity distribution.
} 
Substituting (ZCPC) into (FEC) for countries $i, j=\{H, F\}$ we obtain a system of equations,

$$
\frac{\delta(k+1-\sigma)}{f(\sigma-1)}=\frac{\left(\varphi_{H}^{\min }\right)^{k}}{f_{e}-s_{H}}\left[\left(\varphi_{H}^{*}\right)^{-k}+\phi\left(\varphi_{F}^{*}\right)^{-k}\right], \quad \frac{\delta(k+1-\sigma)}{f(\sigma-1)}=\frac{\left(\varphi_{F}^{\min }\right)^{k}}{f_{e}-s_{F}}\left[\left(\varphi_{F}^{*}\right)^{-k}+\phi\left(\varphi_{H}^{*}\right)^{-k}\right]
$$

which gives rise to the following solutions for the equilibrium domestic cutoffs:

$$
\varphi_{H}^{*}=\left(\frac{\zeta \chi\left(1-\phi^{2}\right)}{\zeta \chi-\phi}\right)^{\frac{1}{k}}\left[\frac{f(\sigma-1)\left(\varphi_{H}^{\min }\right)^{k}}{\delta\left(f_{e}-s_{H}\right)(k+1-\sigma)}\right]^{\frac{1}{k}}, \quad \varphi_{F}^{*}=\left(\frac{1-\phi^{2}}{1-\phi \zeta \chi}\right)^{\frac{1}{k}}\left[\frac{f(\sigma-1)\left(\varphi_{F}^{\min }\right)^{k}}{\delta\left(f_{e}-s_{F}\right)(k+1-\sigma)}\right]^{\frac{1}{k}}
$$

$\zeta \equiv\left(f_{e}-s_{H}\right) /\left(f_{e}-s_{F}\right)$ and $\chi \equiv\left(\varphi_{F}^{\min } / \varphi_{H}^{\min }\right)^{k}$ respectively measure the countries' relative effective entry costs and relative technology. Note that the cutoff expressions in (10) converge against the autarky cutoff levels given in (5) if exporting becomes prohibitively costly (i.e., if $\phi \rightarrow 0)$. If countries are symmetric $(\varsigma=\chi=1)$ we can verify the selection effect of opening up to trade by noting that $\varphi_{i}^{*}=(1+\phi)^{1 / k} \varphi_{i, a u t}^{*}>\varphi_{i, a u t}^{*}$. That is, trade integration per se raises the average productivity in the two symmetric countries by forcing less efficient firms to exit and by reallocating market shares towards more efficient producers.

In the asymmetric case, assuming that $F$ is the laggard country in terms of effective entry costs and/or technology, we have $\varsigma \leq 1$ and $\chi \leq 1$. We then need to impose the condition that these asymmetries are modest relative to the trade openness, namely $\varsigma \cdot \chi>\phi$, to ensure that $\varphi_{i}^{*}>0$ for $i=H, F$. In this case we obtain $\varphi_{x F}^{*}>\varphi_{x H}^{*}>\varphi_{H}^{*}>\varphi_{F}^{*}$. The firms from the country with better technology and/or lower effective entry costs have higher average productivity. ${ }^{7}$

\subsection{Trade balance condition and equilibrium allocation}

To complete the description of the open economy equilibrium we first need to derive the allocation of labour $\gamma_{i}$ in both countries. We use the aggregate trade balance for country $H$ :

$$
M_{H} p_{x H} r_{x H}\left(\tilde{\varphi}_{x H}\right)=M_{F} p_{x F} r_{x F}\left(\tilde{\varphi}_{x F}\right)+\left(1-t_{H}-\beta\right) L_{H}-\left(1-\gamma_{H}\right) L_{H}
$$

The LHS of (11) denotes the value of country $H$ 's manufacturing exports, and the first term on the RHS are the respective manufacturing imports from country $F$. If manufacturing trade is not balanced between $H$ and $F$, the overall trade balance is closed by net exports of the numeraire good (the sum of the second and third term on the RHS). Using this trade balance condition we can state the following result which is proven in appendix B:

\footnotetext{
${ }^{7}$ Assume $\varsigma=1$ and $\phi<\chi<1$. Note that (10) then implies $\partial \varphi_{H}^{*} / \partial \phi>0$ while the sign of $\partial \varphi_{F}^{*} / \partial \phi$ is positive (negative) if $\chi$ is above (below) $2 \phi /\left(1+\phi^{2}\right)$. That is, trade integration clearly raises the cutoff and average productivity of the technologically leading country, while the laggard country only gains from trade integration if it only modestly backwards. Demidova (2008) proves this result for general distribution functions $g(\varphi)$.
} 
Lemma 1 In the open economy equilibrium the labour share allocated to manufacturing production in country $i=H, F$ is given by

$$
\gamma_{H}=\beta\left(\frac{1-\phi \varsigma \chi(1+\lambda)}{1-\phi \varsigma \chi}+\frac{\phi}{\varsigma \chi-\phi}\right)+t_{H}, \quad \gamma_{F}=\beta\left(\frac{1}{1-\phi \varsigma \chi}-\frac{\phi}{\lambda(\varsigma \chi-\phi)}\right)+t_{F}
$$

where $\lambda \equiv L_{F} / L_{H}$ denotes relative country size.

Note that a higher tax rate in country $i$ increases the manufacturing share in that country, as numeraire consumption is squeezed and entry costs are lowered. Furthermore, recall that due to identical preferences across countries the per-capita manufacturing expenditure of every household is given by $\beta$. It immediately follows from (12) that $\gamma_{H}=\gamma_{F}=\beta+t$ if countries are symmetrical $(\lambda=\varsigma=\chi=1)$, and $\gamma_{i}=\beta+t_{i}$ if trade costs are prohibitive $(\phi \rightarrow 0)$. To ensure that the numeraire sector is active after trade in both countries in the asymmetric case we need to impose parameter restrictions such that $0<\gamma_{i}<1$ for $i=H, F$. These conditions, spelled out in appendix B, require that the degree of asymmetry is modest relative to trade openness, and that the per-capita manufacturing expenditure $\beta$ is sufficiently small. Under these conditions, the country that is larger and/or technologically leading and/or has lower effective entry costs produces the bulk of varieties and has a trade surplus in that sector.

Using $\gamma_{H}$ and $\gamma_{F}$ as given in (12), it is straightforward to derive the equilibrium masses of entrants $M_{i}^{E}$, surviving firms $M_{i}$ and exporters $M_{x i}$, and the available consumption variety $\left(M_{t i}=M_{i}+M_{x j}\right)$ for both countries. Finally, the CES price index is $P_{i}=M_{t i}^{1 /(1-\sigma)} /\left(\rho \cdot \tilde{\varphi}_{t i}\right)$, where $\tilde{\varphi}_{t i}$ denotes the average productivity among all (domestic and foreign) firms active in country $i$. Using the fact that $M_{t i}=\beta L_{i} / r_{i}\left(\tilde{\varphi}_{t i}\right)$ in equilibrium, and substituting $r_{i}\left(\tilde{\varphi}_{t i}\right)=\left(\tilde{\varphi}_{t i} / \varphi_{i}{ }^{*}\right)^{\sigma-1} \sigma f$, this leads to the following expression for total welfare in $i$ :

$$
W_{i}=L_{i}\left[y_{i}-\beta \cdot \ln P_{i}+b\right]=L_{i}\left[1-t_{i}+\beta\left(\ln \varphi_{i}^{*}(\cdot)+\frac{1}{\sigma-1} \cdot \ln L_{i}\right)+b\right]
$$

Taking eqs. (10), (13) and the conditions for non-specialization, we show in appendix B that the leading country in terms of technology or size has more entrants, more surviving firms, higher consumption diversity, lower CES price index and higher welfare.

When it comes to effective entry costs the welfare implications of country differences are not obvious, because lower effective entry costs require higher taxes to finance the subsidies. Before turning to the endogenous determination of the subsidy-tax schedule it is useful, however, to briefly consider how an exogenous change in these costs affects the steady-state equilibrium of the open economy model while neglecting the implied changes in tax rates. 
Recall that in the autarky case a decrease of sunk entry cost leads to an increase in the mass of entrants and the cutoff productivity, while ex-ante expected profits and the mass of surviving firms remain constant (see section 2). In the open economy matters are more complex. Suppose that effective entry costs in country $F$ decrease, which implies an increase of the term $\varsigma$. It follows from (10) and the expressions reported in appendix B that we not only have more entrants $M_{F}^{E}$ and higher threshold productivity $\varphi_{F}^{*}$ in country $F$, but also a rise in the mass of surviving firms $M_{F}$. In contrast, steady-state values of $M_{H}^{E}, \varphi_{H}^{*}$ and $M_{H}$ are decreasing in $\varsigma$. The reason is the following: The lower effective entry costs trigger entry and induce tougher selection in $F$, similarly as under autarky, but the higher domestic cutoff productivity $\varphi_{F}^{*}$ now also implies a rising export cutoff $\varphi_{x H}^{*}$. It becomes more difficult for firms from $H$ to break into the more competitive market in $F$. This puts downward pressure on expected profits $\bar{\pi}_{H}$ and reduces the incentive for entry ( $M_{H}^{E}$ decreases). The stationary equilibrium in $H$ is restored by a combination of higher survival probability (lower $\varphi_{H}^{*}$ ) and lower firm turnover $M_{H}$. This in turn facilitates entry of firms from $F$ into their export market (decrease of $\varphi_{x F}^{*}$ ), which further boosts ex-ante expected profits $\bar{\pi}_{F}$. Restoring the stationary equilibrium in $F$ now implies a combination of tougher selection and higher firm turnover. Put differently, country $F^{\prime}$ 's entry cost reduction induces a selection effect in $F$ which in turn makes export market entry easier for firms from $F$ and more difficult for the firms from $H$.

\section{Taxes and entry subsidies: Symmetrical open economies}

We now turn to the determination of the endogenous entry subsidies. The analysis in this section assumes that countries $H$ and $F$ are symmetrical in terms of size and technology, which allows for closed-form solutions for the (equilibrium and optimal) policies. First we deal with the Nash-equilibrium that results when $H$ and $F$ behave non-cooperatively (section 4.1) before addressing the case where $H$ and $F$ cooperate (section 4.2). In section 4.3 we compare the policies and discuss the economic intuition.

\subsection{Nash equilibrium policy}

The government in country $i$ maximizes total welfare $W_{i}$ as given in (13) with respect to the subsidy $s_{i}$, taking into account the budget constraint, and taking the policy parameters of the other country $\left\{t_{j}, s_{j}\right\}$ as given. Similar as under autarky the first order condition commands that (constant) marginal costs of taxation equal marginal benefits 


$$
\beta \cdot \hat{\varphi}_{i}^{*}=1, \quad \text { where } \hat{\varphi}_{i}^{*}=\frac{d \ln \varphi_{i}^{*}}{d t_{i}}=\frac{1}{\varphi_{i}^{*}} \cdot \frac{d \varphi_{i}^{*}}{d s_{i}} \cdot \frac{d s_{i}}{d t_{i}}
$$

In the case of symmetrical technologies $\left(\chi=1\right.$ and $\varphi_{H}^{\min }=\varphi_{F}^{\min }=1$ for convenience) the cutoff productivity $\varphi_{i}^{*}$ from (10) simplifies to

$$
\varphi_{i} *\left(s_{i}, s_{j}\right)=\left(\frac{f(\sigma-1)}{\delta(k+1-\sigma)} \cdot \frac{1-\phi^{2}}{\left(f_{e}(1-\phi)-s_{i}+\phi s_{j}\right)}\right)^{1 / k} .
$$

Furthermore, using $\lambda=1\left(L_{H}=L_{F}=L\right)$ and the expressions for $M_{i}^{E}$ as given in eq. (B5) in appendix B, the government budget constraint reads as

$$
t_{i} \cdot L_{i}=s_{i} \cdot M_{i}^{E}\left(s_{i}, s_{j}\right)=s_{i} \cdot \frac{(\sigma-1) \beta L}{\sigma k \xi}\left(f_{e}(1-\phi)^{2}+2 \phi s_{i}-s_{j}\left(1+\phi^{2}\right)\right),
$$

for $i, j=\{H, F\}, i \neq j$ where $\xi \equiv\left(f_{e}(1-\phi)-s_{H}+\phi s_{F}\right)\left(f_{e}(1-\phi)-s_{F}+\phi s_{H}\right)$. This budget constraint (16) can be expressed as an implicit function $g_{i}\left(t_{i}, s_{i}, s_{j}\right)=t_{i} L_{i}-s_{i} M_{i}^{E}\left(s_{i}, s_{j}\right)=0$. Postulating non-cooperative government behaviour we can solve for the Nash equilibrium in the determination of entry subsidies and taxes. We can use (15) and (16) to calculate

$$
\frac{1}{\varphi_{i}^{*}} \cdot \frac{d \varphi_{i}^{*}}{d s_{i}}=\frac{1}{k\left(f_{e}-s_{i}-\phi\left(f_{e}-s_{j}\right)\right)} \quad \text { and } \quad \frac{d s_{i}}{d t_{i}}=-\frac{\partial g_{i} / \partial t_{i}}{\partial g_{i} / \partial s_{i}}=\frac{k \sigma \xi^{2}}{\beta(\sigma-1)} \cdot \frac{1}{\tilde{\xi}_{i}}
$$

where the term $\tilde{\xi}_{i}$ for $i, j=\{H, F\}, i \neq j$ is given by $\tilde{\xi}_{i}=\phi s_{j}\left(s_{i}{ }^{2}+s_{j}{ }^{2}-4 \phi s_{i} s_{j}+\phi^{2}\left(s_{i}{ }^{2}+s_{j}{ }^{2}\right)\right)$ $+f_{e}^{3}(1-\phi)^{4}-2 f_{e}^{2}(1-\phi)^{2}\left(s_{j}\left(1-\phi+\phi^{2}\right)-2 \phi s_{i}\right)+f_{e}(1-\phi)^{2}\left(s_{j}{ }^{2}\left(1-\phi+\phi^{2}\right)-4 \phi s_{i} s_{j}-\phi s_{i}{ }^{2}\right)$.

Using these expressions in the first order condition (14) yields $\hat{\varphi}_{i} *\left(s_{i}, s_{j}\right)$, which leads to the government reaction functions $\beta \cdot \hat{\varphi}_{i} *\left(s_{i}, s_{j}\right)-1=0$ for the two countries. In the present case with equally large and productive countries $(\lambda=\chi=1)$ it is clear that these reaction functions are symmetric, and that the Nash equilibrium subsidy must be identical in the two countries $\left(s_{H} *=s_{F} *=s^{*}\right)$. Exploiting this symmetry property we can state

Proposition 3 Consider two symmetrical open economies. The government in each country collects income taxes and subsidizes sunk entry costs for domestic firms. The tax rate and the entry subsidy in the non-cooperative Nash equilibrium are given by

$$
s^{*}=\frac{f_{e}(1-\phi)(1+\phi(\sigma-1))}{\sigma+\phi(\sigma-2)} \quad \text { and } \quad t^{*}=\frac{\beta}{\sigma k} \frac{(1-\phi)(1+\phi(\sigma-1))}{\left(1+\phi^{2}\right)} .
$$

Proof: In the case with symmetrical countries we have

$$
\frac{1}{\varphi^{*}} \cdot \frac{d \varphi^{*}}{d s}=\frac{1}{k\left(f_{e}-s\right)(1-\phi)} \quad \text { and } \quad \frac{d s}{d t}=\frac{\sigma k\left(f_{e}-s\right)^{2}(1-\phi)^{2}}{\beta(\sigma-1)\left(f_{e}(1-\phi)^{2}+2 \phi s\right)}
$$


Hence, marginal benefits of entry subsidization in the symmetrical open economy case read as

$$
\beta \cdot \hat{\varphi}^{*}=\frac{\sigma\left(f_{e}-s\right)(1-\phi)}{(\sigma-1)\left(f_{e}(1-\phi)^{2}+2 \phi s\right)} \geq 0 .
$$

Note that (18) implies positive but decreasing marginal benefits of entry subsidization, $\partial\left(\beta \cdot \hat{\varphi}^{*}\right) / \partial s<0$ with $\beta \cdot \hat{\varphi}^{*} \rightarrow \sigma\left(f_{e}-s\right) / f_{e}(\sigma-1)>0$ if $\phi \rightarrow 0$ and $\beta \cdot \hat{\varphi}^{*} \rightarrow 0$ if $\phi \rightarrow 1$. Solving $\beta \cdot \hat{\varphi}^{*}=1$ yields the Nash equilibrium subsidy $s^{*}$ as given in (17). Furthermore, with symmetrical countries the budget constraint (16) simplifies to $s=\sigma k t f_{e} /[\beta(\sigma-1)+\sigma k t]$. Plugging in $s^{*}$ and solving for $t$ then yields the equilibrium tax rate $t^{*}$ as given in (17).

\subsection{Cooperative entry subsidization policy}

Turning to the case where the governments in $H$ and $F$ cooperate, recall that marginal utility of income is equal to one everywhere due to quasi-linear preferences. A utilitarian social welfare function thus precisely measures joint welfare, which in the case with two symmetrical, non-specialized countries can be written as

$$
\Omega=W_{H}+W_{F}=L\left[1-t_{H}+\beta \ln \varphi_{H}^{*}(\cdot)+1-t_{F}+\beta \ln \varphi_{F}^{*}(\cdot)+b^{\prime}\right],
$$

where $b^{\prime} \equiv 2 b+\frac{2 \beta}{\sigma-1} \ln L$ is a constant. This objective function (19) is maximized while taking into account the overall budget constraint of the two countries,

$$
g=L\left(t_{H}+t_{F}\right)-s_{H} M_{H}^{E}\left(s_{H}, s_{F}\right)-s_{F} M_{F}^{E}\left(s_{H}, s_{F}\right)=0 \leftrightarrow t_{F}=\frac{1}{L}\left(s_{H} M_{H}^{E}(\cdot)+s_{F} M_{F}^{E}(\cdot)\right)-t_{H}
$$

Substituting (20) into (19) we can express joint welfare $\Omega$ solely as a function of $s_{H}$ and $s_{F}$, $\Omega\left(s_{H}, s_{F}\right)$. Taking first-order conditions, and imposing symmetry $s_{H}=s_{F}=s$ after taking derivatives, we can characterize the cooperative entry subsidization policy as follows:

Proposition 4 Consider two symmetrical open economies where governments cooperatively set entry subsidies and finance the expenses with lump-sum taxes. The cooperative policy is equivalent to the tax and entry subsidy under autarky characterized in eq. (9).

Proof: Differentiating $d \Omega / d s_{i}$ and imposing $s_{i}=s_{j}=s$ for $i, j=\{H, F\}, i \neq j$ yields $d \Omega / d s=\beta L\left(f_{e}-\sigma s\right) / \sigma k\left(f_{e}-s\right)^{2}=0$. Solving this first-order condition we obtain $s=f_{e} / \sigma$ which is equivalent to $s_{\text {aut }}^{*}$. Using $t_{H}=t_{F}=t$ and $s_{H}=s_{F}=s=f_{e} / \sigma$ in (20) we obtain $g=2 L\left(\frac{\beta}{\sigma k}-t\right)=0$, hence $t=\beta / \sigma k$ which is equivalent to $t_{\text {aut }}^{*}$.

If the two symmetrical countries coordinate their policies, they behave as a single country under autarky in our framework and indirectly correct for the monopoly distortion in the 
manufacturing sector by subsidizing firm entry. Again it should be noted that this cooperative choice of entry subsidies is only a constrained optimum. ${ }^{8}$

\subsection{Entry subsidies: Nash equilibrium versus cooperative policy}

Using propositions 1, 3 and 4 we can now single out some important observations about the Nash-equilibrium and the cooperative entry subsidization policy for the case of two symmetrical open economies in the course of trade integration. These insights, which follow directly from (9) and (17), can be summarized as follows:

Proposition 5 a) The entry subsidy and the tax in the Nash-equilibrium are hump-shaped with respect to trade openness. Specifically, we have $\left\{s^{*}>s_{\text {aut }}^{*}, t^{*}>t_{\text {aut }}^{*}\right\}$ and thus oversubsidization for low, and $\left\{s^{*}<s_{\text {aut }}^{*}, t^{*}<t_{\text {aut }}^{*}\right\}$ and thus under-subsidization for high levels of trade openness $\phi$, with $\left\{t^{*}=t_{\text {aut }}^{*}, s^{*}=s_{\text {aut }}^{*}\right\}$ at $\phi=(\sigma-2) / \sigma$.

b) With prohibitively high trade costs the Nash-equilibrium coincides with the autarkic (=coordinated) policy, i.e., $s^{*}=s_{\text {aut }}^{*}$ and $t^{*}=t_{\text {aut }}^{*}$ for $\phi=0$.

c) With free trade the Nash-equilibrium policy implies a tax rate of zero and no entry subsidies $\left(s^{*}=0\right.$ and $t^{*}=0$ at $\left.\phi=1\right)$.

Figure 1 illustrates the tax and entry subsidy in the open economy Nash-equilibrium (thick solid lines), and with cooperative policy determination (broken lines).

\section{[FIGURE 1 ABOUT HERE]}

The figures show that, starting from an autarkic situation, gradual trade liberalization first leads to increasing taxes and entry subsidies in the Nash-equilibrium. Then, at a certain stage of openness, taxes and entry subsidies start to decrease with further integration until they eventually fall short of the cooperative levels and ultimately converge to zero when trade becomes completely free.

What is the intuition for these results? In the open economy there are two motives for governments to subsidize firm entry. First, this policy tool indirectly corrects for the distortions due to imperfect competition in the manufacturing industry. Second, the crosscountry transmission of the effects makes entry subsidies a strategic policy tool. The cooperative solution internalizes all cross-country externalities and thereby only follows the

\footnotetext{
${ }^{8}$ Similarly as under autarky, the first-best allocation can only be achieved with direct consumption subsidies. We show in appendix $\mathrm{C}$ that, if consumption subsidies were available, the cooperative solution commands such a subsidy at the rate $1 / \sigma$ as under autarky. Moreover, we also show that the non-cooperative choice and the cooperative choice of consumption subsidies coincide. This parallels the result by Haufler and Pflüger (2004) for the Dixit-Stiglitz model without firm heterogeneity.
} 
first motivation. Proposition 4 shows that this cooperative policy is equivalent to the tax and entry subsidy in the autarky case, and is therefore independent of the level of trade openness. Any deviation of the Nash-equilibrium from the cooperative policy in the range of $\phi$ therefore represents the effect of trade integration on the strategic motives for entry subsidization. Proposition 5 shows that the net externality exerted by the non-cooperative choice of policy schemes is ambiguous since there are two competing effects.

To understand the non-monotonic effect of trade liberalization on the Nash-equilibrium, it is useful to study the marginal benefits of entry subsidization $\left(\beta \cdot \hat{\varphi}^{*}\right)$ in greater detail. If freer trade increases (decreases) $\beta \cdot \hat{\varphi}^{*}$, this would push for an increase (a decrease) of $t^{*}$ and $s^{*}$, since the marginal costs of taxation are constant. Differentiating (18) with respect to $\phi$, evaluated at the equilibrium subsidy $s_{H}=s_{F}=S^{*}$, implies the following expression

$$
\begin{aligned}
{\frac{d\left(\beta \cdot \hat{\varphi}^{*}\right)}{d \phi}}_{\left.\right|_{s=s^{*}}} & \frac{\beta}{t} \cdot\left(\frac{d s}{d t} \cdot \frac{t}{s}\right)_{\mid s=s^{*}} \cdot \frac{d}{d \phi}\left(\frac{s}{\varphi^{*}} \frac{d \varphi^{*}}{d s}\right)_{\mid s=s^{*}}+\frac{\beta}{t} \cdot\left(\frac{s}{\varphi^{*}} \frac{d \varphi^{*}}{d s}\right)_{\mid s=s^{*}} \cdot \frac{d}{d \phi}\left(\frac{d s}{d t} \cdot \frac{t}{s}\right)_{\mid s=s^{*}} \\
& =\frac{1}{1-\phi}-\frac{2(1+\phi)(1+\phi(\sigma-1))}{\sigma(1-\phi)\left(1+\phi^{2}\right)}=\frac{(\sigma-2)\left(1-\phi^{2}\right)-2 \phi \sigma}{\sigma(1-\phi)\left(1+\phi^{2}\right)} .
\end{aligned}
$$

The overall sign of (21) is ambiguous. On the one hand we find that an additional $€$ worth of subsidies generates a more substantial increase of the cutoff productivity the freer trade is $\left(d^{2} \varphi^{*} /(d s d \phi)>0\right)$. This higher effectiveness of the subsidy is represented by the positive first term in (21), which is increasing in $\phi$. On the other hand, it becomes increasingly more difficult to finance an additional $€$ worth of subsidies by raising taxes in the open economy Nash-equilibrium, as the mass of entrants becomes extremely responsive to the entry subsidies in the two countries if openness is high. This is represented by the negative second term $\left(d^{2} s /(d t d \phi)<0\right)$ which is decreasing in $\phi$. When taken together, the overall sign of $d\left(\beta \cdot \hat{\varphi}^{*}\right) / d \phi$ at $s=s^{*}$ is positive at low, and negative at high levels of $\phi$. In other words, gradual trade integration first amplifies the marginal benefits of subsidization and leads to a higher tax and subsidy in the Nash equilibrium as the former effect dominates the latter. Later on, their relative strength switches and further trade integration decreases the marginal benefits of entry subsidies, and thus the size of the subsidy programme.

Turning to observation $b$ ) of proposition 5 , this result immediately follows from the fact that there is no incentive for strategic entry subsidization if trade costs are prohibitively high $(\phi=0)$. There is still the non-strategic motive for subsidies, which the governments take into account and behave as under autarky. Finally, turning to observation c), there is no motive for further entry subsidization in the Nash-equilibrium if trade is completely free. In this constellation all firms in this economy are already exporters, so that there are no further 
strategic motives to hinder foreign market entry and to ease domestic market entry in the other country. ${ }^{9}$

\section{Asymmetric open economies}

In this section we turn to the Nash equilibrium in the case of two asymmetric countries that can differ in technology or size. Allowing for asymmetries unfortunately rules out analytical solutions for the equilibrium entry subsidy and tax. However, it is possible to derive explicit expressions for the government reaction functions and to solve for the Nash-equilibrium numerically. First, using (10) we obtain the following expressions for the marginal productivity gain associated with the entry subsidy in countries $H$ and $F$, respectively.

$$
\frac{1}{\varphi_{H} *} \cdot \frac{d \varphi_{H} *}{d s_{H}}=\frac{\chi}{k\left(\chi\left(f_{e}-s_{H}\right)-\phi\left(f_{e}-s_{F}\right)\right)}, \frac{1}{\varphi_{F}^{*}} \cdot \frac{d \varphi_{F} *}{d s_{F}}=\frac{1}{k\left(f_{e}-s_{F}-\phi \chi\left(f_{e}-s_{H}\right)\right)}
$$

Suppose that $F$ is the technologically laggard country $(\chi<1)$. Equation (22) reveals that if $\chi$ increases and country $F$ catches up, every $€$ worth of entry subsidies generates a more substantial cutoff increase in that country, ceteris paribus, while the entry subsidies in the other country $H$ become less effective. The budget constraints can be written as follows

$$
\begin{gathered}
g_{H}=\hat{\xi} \cdot\left[s_{H} L_{H} \chi\left(\left(f_{e}-s_{F}\right)\left(1+\phi^{2}(2 \lambda-1)-2 \phi \lambda \chi\left(f_{e}-s_{H}\right)\right)\right]-t_{H} L_{H}=0\right. \\
g_{F}=\hat{\xi} \cdot\left[s_{F} L_{F} \cdot\left(\chi\left(f_{e}-s_{H}\right)\left(1+\phi^{2}\right)-2 \phi\left(f_{e}-s_{F}\right)\right)\right]-t_{F} L_{F}=0
\end{gathered}
$$

where $\hat{\xi} \equiv \frac{\beta(\sigma-1)}{\sigma k\left(\chi\left(f_{e}-s_{H}\right)-\phi\left(f_{e}-s_{H}\right)\right)\left(f_{e}-s_{F}-\phi \lambda \chi\left(f_{e}-s_{H}\right)\right)}$, which can be used to derive $d s_{i} / d t_{i}=-\left(\partial g_{i} / \partial s_{i}\right)^{-1}$ for $i=\{H, F\}$.

Substituting this together with (22) into the first-order condition (14) we obtain the government reaction functions for countries $H$ and $F$, which depend on relative technology and country sizes, $R F_{i}\left(s_{i}, s_{j}, \chi, \lambda\right)=\beta \cdot \hat{\varphi}_{i} *\left(s_{i}, s_{j}, \chi, \lambda\right)-1=0$ for $i, j=\{H, F\}, j \neq i$. As stated before, we cannot solve this equation system explicitly for closed-form solutions $s_{H}{ }^{*}, s_{F} *$ which satisfy $R F_{i}=0$ and $s_{i}{ }^{*} \geq 0$. However, we can provide some intuition on the effects of technology and size differences by means of numerical examples.

In table 1 we illustrate the Nash equilibrium subsidies in various constellations. The left half of the table refers to cases where country $H$ is technologically ahead of $F$, whereas the right

\footnotetext{
${ }^{9}$ By the definition of $\phi$, at maximum openness $\phi=1$ we have $L H S \equiv \tau^{k(\sigma-1)}=\left(f / f_{x}\right)^{(k+1-\sigma)} \equiv R H S$. Since $\tau \geq 1, \quad f_{x} \geq f$ and $k-1>\sigma>1$ it follows that $L H S \geq 1$ and $R H S \leq 1$. The only consistent constellation is therefore $L H S=R H S=1$, i.e., $\tau=1$ and $f_{x}=f$. In other words, in a constellation with maximum openness $(\phi=1)$ all firms in this symmetrical two-country economy are exporters $\left(p_{x}=\Lambda^{-k}=1\right)$.
} 
half refers to cases where $H$ is larger than $F$. In the first line on both halves we still report the benchmark cases with identical countries. In the second and third line we consider cases with a disparity (in technology or, respectively, in size) between countries $H$ and $F$, where the magnitude of the disparity is stronger in the third than in the second line. For each constellation of the country disparity we then report the Nash-equilibrium subsidy that would result with low, medium and high trade openness, respectively. ${ }^{10}$

\section{[TABLE 1 HERE]}

Table 1 yields three main insights. Firstly, the technologically leading country $H$ has a lower equilibrium entry subsidy than the laggard country $F$. This can be seen by comparing $s_{H}^{*}$ and $s_{F}^{*}$ in the left half of the table for any given constellation of trade openness and strength of the technological gap. This result is quite intuitive. In country $H$ entrants draw from a more favorable distribution and, thus, have a higher ex-ante probability to succeed in the market than in country $F$. Put differently, surviving firms in $H$ are on average more productive and successful as exporters than firms from country $F$. This implies that there is less need in country $H$ to subsidize entry in order to grasp a competitive advantage in international trade.

Secondly, the examples in the right half of table 1 suggest that subsidies are also lower in larger countries. What is the intuition for this result? Recall from above that, neglecting entry subsidies, there are more entrants, more surviving firms and higher consumption diversity in larger countries. Due to these market size effects, country $H$ is therefore relatively less affected by the exporting firms from country $F$ than vice versa. It is therefore less inclined to raise taxes in order to subsidize further entry of domestic firms and to gain competitiveness relative to the (few) firms from the small country.

Thirdly and finally, the examples suggest that there is still a hump-shaped relationship between subsidies and trade openness, similarly as in the case with symmetrical countries. For any given (technological or size) disparity we find that the subsidy in both countries first increases and then decreases as trade gradually becomes freer. These numerical results for the Nash-equilibrium verify the hump-shaped pattern shown in figure 1.

\section{Empirical analysis}

Our theoretical model thus predicts a U-shaped relationship between trade openness and effective entry costs $\tilde{f}_{e}^{*}=f_{e}-s^{*}$. In this final section we provide a brief empirical analysis whether these theoretical results are supported by the data.

\footnotetext{
${ }^{10}$ For the sake of numerical simulation we assume fixed values for the parameters $f$ and $f_{x}$ in all examples. Different levels of trade openness $\phi$ thus result from different levels of iceberg trade costs $\tau$. Furthermore, in table 1 we focus on the equilibrium subsidies and neglect the corresponding tax rates that satisfy the balanced budget constraint. In the examples the tax rate follows a similar pattern as the subsidies.
} 


\subsection{Data and estimation}

Djankov et al. (2002) have compiled data on effective entry costs for 85 countries in the year 1999 that include both pecuniary and time costs for obtaining all necessary permits and complying with all other relevant official requests to set up a firm. This data does not directly include government subsidies to entrepreneurs, such as start-up grants etc., but focuses on the legal procedures that are officially required for starting a business. However, we hypothesize that countries with stiffer entry regulation and higher effective entry costs are also less prone to paying direct pecuniary subsidies. We therefore use this measure by Djankov et al. (2002) as our proxy for the variable $\tilde{f}_{e} *$ which ranges from $2.5 \%$ of Canadian GDP per capita (483 $\$$ ) to $495 \%$ of GDP per capita (945\$) in the Dominican Republic. ${ }^{11}$

We augment this data set with information on trade openness at the country level, sticking to some standard proxies that have been widely used in the literature. The most common openness indicator is trade intensity which is defined for country $i$ as the sum of total exports and imports over GDP, $T I_{i}=\left(\operatorname{Exp}_{i}+\operatorname{Imp}_{i}\right) / G D P_{i}$. Squalli and Wilson (2006) have criticized this conventional approach because it typically classifies some of the most important trading nations (such as USA or Germany) as relatively closed economies. They suggest an alternative "composite trade intensity" (CTI), which corrects the standard $T I$ for the importance of a country to overall world trade. The CTI is defined as follows

$$
C T I_{i}=\frac{n \cdot\left(\operatorname{Exp}_{i}+\operatorname{Imp}_{i}\right)^{2}}{G D P_{i} \cdot \sum_{j=1}^{n}\left(\operatorname{Exp}_{j}+\operatorname{Imp}_{j}\right)},
$$

where $n$ is the number of countries. Squalli and Wilson (2006) provide $T I$ - and CTI -based openness levels for 136 different countries and for the year 2000. Matching this information with the entry cost data by Djankov et al. (2002), we end up with a sample of 81 countries. To be consistent with the theoretical model we furthermore include population size and "technology" of these countries in the empirical analysis. The latter is proxied by GDP/employment (in \$ for 1999). The main estimation equation is given by

$$
\tilde{f}_{e, i}=\alpha+\beta_{1} \cdot \text { OPEN }_{i}+\beta_{2} \cdot \text { OPEN }_{i}^{2}+\beta_{3} \cdot\left(\text { GDP }_{i} / \text { empl }_{i}\right)+\beta_{4} \cdot \text { Population }_{i}+\varepsilon_{i},
$$

where $O P E N_{i}$ is the $T I$ - or $C T I$-based openness measure for country $i$, and $\varepsilon_{i}$ is an error term. We estimate this cross-sectional equation by using OLS with robust standard errors. ${ }^{12}$

\footnotetext{
${ }^{11}$ The absolute effective entry costs range from $42.38 \$$ in Mongolia (12\% of GDP per capita) to $10,928.18 \$$ in Austria (42\% of GDP per capita). As in Djankov et al. (2002) we measure effective entry costs relative to the countries' income level in the empirical analysis.

${ }^{12}$ In appendix D we provide additional information about the data including a list of the 81 countries.
} 


\subsection{Results and discussion}

In table 2 we report the results. The left half of the table refers to "unconditional" estimations where we only control for trade openness while in the right half we condition our estimates on population size and labor productivity. In columns 1 and 3 we have used the $C T I$-measure of trade openness, while columns 2 and 4 refer to the more conventional TI -measure.

\section{[TABLE 2 HERE]}

Consistently across all specifications we find that $\beta_{1}$ is negative and highly statistically significant while $\beta_{2}$ is significantly positive. That is, both unconditionally and conditional on size and technology we do in fact find a U-shaped relationship between trade openness and effective entry costs, as predicted by our theoretical model.

These estimation results should be taken with a grain of salt. First and foremost, effective entry costs are likely to be measured with error (see Djankov et al. 2002 for an in-depth discussion) and do not directly reflect the entry subsidies which are the main focus of our model. Second, trade openness data refer to export intensities rather than exogenous transport costs. Finally, there may be issues of endogeneity as the decisions of foreign firms to enter a domestic market (and, thus, the openness level of the domestic country) are likely to be affected by the entry regulation that is adopted in this economy. Inherent data problems of measuring subsidies, effective entry costs, and trade openness more accurately across countries prevent us from a more detailed analysis at this stage. We still believe that our simple empirical analysis leads to some useful insights. In particular we conclude that the one main result of our theoretical model is consistent with the stylized facts about effective entry costs in open economies that appear in the data.

\section{Conclusions}

In this paper we have a developed a two-country model where governments engage in entry subsidization of domestic firms. One motive for this policy, valid already in an autarkic scenario, is to indirectly correct the distortions that result from imperfect competition. In open economies there is then also a second, strategic motive for entry subsidies, namely to tighten selection in the own country which improves the average productivity of domestic firms and makes market entry for foreign firms more difficult. Put differently, even though entry subsidies have - at first glance - no direct implications for exporting decisions of domestic or foreign firms as they do not affect fixed or variable trade costs directly, there are still distinct general equilibrium implications for market entry considerations and exporting probabilities. This can render entry subsidies an interesting strategic policy tool for governments, because 
entry regulation for new firms is typically conceived as a purely domestic policy area. Unlike some of the classical tools of trade policy, such as export subsidies or import tariffs, these entry subsidies are typically not scrutinized by international organizations like the WTO. Our analysis shows that due to general equilibrium interactions there are, however, distinct crosscountry transmissions of this "domestic" policy and potential gains from policy cooperation. Our model predicts a U-shaped relationship between trade openness and effective entry costs in the non-cooperative Nash equilibrium. If trade openness is low, trade integration first leads to higher entry subsidies and thus to lower effective entry costs. Later on, at higher levels of openness, integration leads to less subsidization. This U-shaped pattern also shows up in cross-country data. To set our findings into perspective, let us refer to specification 4 of table 1 which uses the more easily interpretable trade intensity ( $T I$ )-based openness measure. Conditional on size and technology differences we find that effective entry costs achieve a global minimum at a quite high openness level equal to $(\operatorname{Exp}+\operatorname{Imp}) / G D P=184.4 \%$. Only 3 out of 81 countries exhibit TI -based openness beyond this critical level (Hong Kong, Singapore and Malaysia). The remaining 78 countries, which include all OECD members, are actually located in the downward-sloping range of the U-shaped relationship. These numbers suggest that further trade integration may put downward pressure on effective entry costs for the majority of countries. In terms of our model this would imply that most countries - being exposed to further trade integration - may actually increase their efforts to engage in strategic entry subsidization in the future.

\section{Literature}

Baldwin, R. (2005), Heterogeneous firms and trade: Testable and untestable properties of the Melitz model, NBER Working Paper 11471, Cambridge (Mass.)

Baldwin, R. and T. Okubo (2009), Tax reform, delocation and heterogeneous firms, NBER Working Paper 15109, Cambridge (Mass.)

Behrens, K., G. Mion, Y. Murata and J. Südekum (2009), Trade, wages and productivity, CEPR Discussion Paper 7369, London

Bernard, A., J. Eaton, B. Jensen and S. Kortum (2003), Plants and productivity in international trade, American Economic Review 93: 1268-1290

Brander, J. (1995), Strategic trade policy, in: Grossman, G. and K. Rogoff (eds.), Handbook of international economics, Amsterdam: North Holland.

Bresnahan, T. and P. Reiss (1991), Entry and competition in concentrated Markets, Journal of Political Economy 99: 977-1009

Chor, D. (2009), Subsidies for FDI: Implications from a model with heterogeneous firms, Journal of International Economics 78: 113-125

Cole, M. (2008), Optimal tariffs, tariff jumping, and heterogeneous firms, mimeo, University of Oregon 
Corden, M. (1997), Trade policy and economic welfare, Oxford University Press

Davies, R. and C. Eckel (2009), Tax competition for heterogeneous firms with endogenous entry, forthcoming: American Economic Journal - Economic Policy

Demidova, S. (2008), Productivity improvements and falling trade costs: Boon or Bane?, International Economic Review 49: 1437-1462

Demidova, S. and A. Rodriguez-Clare (2009), Trade policy under firm-level heterogeneity in a small economy, Journal of International Economics 78: 100-112

Dixit, A. and J.. Stiglitz (1977), Monopolistic competition and optimum product diversity, American Economic Review 67: 297-308

Djankov, S., R. La Porta, F. Lopez-de-Silanes, and A. Shleifer (2002), The regulation of entry, Quarterly Journal of Economics 117: 1-37

Flam, H. and E. Helpman (1987), Industrial policy under monopolistic competition, Journal of International Economics 22: 79-102

Geroski, P. (1995), What do we know about entry?, International Journal of Industrial Organization 13: $421-440$

Grossman, G. and E. Helpman (1991), Quality ladders in the theory of economic growth, Review of Economic Studies 58: 43-61

Haufler, A. and M. Pflüger (2004), International commodity taxation under monopolistic competition, Journal of Public Economic Theory 6: 445-470

Helpman, E., M. Melitz and Y. Rubinstein (2008), Estimating trade flows: Trading partners and trading volumes, Quarterly Journal of Economics 123: 441-487

Helpman, E. and P. Krugman (1985), Market structure and foreign trade, Cambridge: MIT Press

Hopenhayn, H. (1992), Entry, exit, and firm dynamics in long run equilibrium, Econometrica 60: $1127-1150$

Jorgensen, J. and P. Schröder (2008), Fixed export cost heterogeneity, trade and welfare, European Economic Review 52: 1256-1274

Krautheim, S. and T.Schmidt-Eisenlohr (200), Heterogeneous firms, profit-shifting FDI and international tax competition, mimeo, European University Institute

Krugman, P. (1980) Scale economies, product differentiation and the pattern of trade, American Economic Review 70: 950-959

Melitz, M. (2003), The impact of trade on intraindustry reallocations and aggregate industry productivity, Econometrica 71: 1695-1725

Melitz, M. and G. Ottaviano (2008), Market size, trade, and productivity, Review of Economic Studies $75,295-316$

Reitzes, J. and O. Grawe (1999), Entry policy and entry subsidies, Review of International Economics 7: 715-731

Squalli, J. and K. Wilson (2006), A new approach to measuring trade openness, Working Paper 06-07, Economic Policy Research Unit, Zayed University

Santarelli, E. and M. Vivarelli (2002), Is subsidizing entry an optimal policy?, Industrial and Corporate Change 11: 39-52 


\section{Appendix A: Consumption subsidies under autarky}

Preliminaries: Consider ad-valorem subsidies to consumption of manufacturing varieties. The consumer price of a variety produced by a firm with productivity level $\varphi$ is now $p_{c}(\varphi)=\left(1-s_{c}\right) \cdot p(\varphi)=\left(1-s_{c}\right) / \rho \varphi$. Total revenue and profits for that firm are then given by $r(\varphi)=p(\varphi) q(\varphi)=\beta L\left(1-s_{c}\right)^{-\sigma}(\rho \varphi P)^{\sigma-1}$ and $\pi(\varphi)=r(\varphi) / \sigma-f$, with CES price level

$$
P=\left(1-s_{c}\right) \cdot M^{1 /(1-\sigma)} /(\rho \tilde{\varphi}),
$$

where average productivity $\tilde{\varphi}$ is defined as in (4). The (FEC) does not change compared to the case without consumption subsidy. The (ZCPC) does not change either, since $r\left(\varphi^{*}\right)=\sigma / f$ and $\tilde{\varphi} / \varphi^{*}=\tilde{\varphi}=\left(\frac{k}{k+1-\sigma}\right)^{1 /(\sigma-1)}$ remain constant. Hence, the consumption subsidy does not affect $\bar{\pi}$ and $\varphi^{*}$ compared to the benchmark case. We still have

$$
\varphi^{*}=\left(\frac{f(\sigma-1)\left(\varphi^{\min }\right)^{k}}{\delta(k+1-\sigma)\left(f_{e}-s\right)}\right)^{1 / k} \quad \bar{\pi}=\frac{f(\sigma-1)}{k+1-\sigma} \rightarrow \bar{r}=\frac{\sigma k f}{k+1-\sigma}
$$

Consumption subsidies do, however, affect the equilibrium mass of entrants and surviving firms. Using (A1) in $\bar{r}=r(\tilde{\varphi})=\beta L\left(1-s_{c}\right)^{-\sigma}(\rho \tilde{\varphi} P)^{\sigma-1}$ yields $M=\beta L /\left(\left(1-s_{c}\right) \bar{r}\right)$. With (A2) and the stationarity condition $\left(1-G\left(\phi^{*}\right)\right) M^{E}=\delta \cdot M$ we then find that both $M$ and $M^{E}$ are higher with than without consumption subsidies (compare (A3) with eq. (5)):

$$
M=\left(\frac{k+1-\sigma}{\sigma k f}\right) \frac{\beta L}{\left(1-s_{c}\right)} \quad M^{E}=\left(\frac{\sigma-1}{\sigma k\left(f_{e}-s\right)}\right) \cdot \frac{\beta L}{1-s_{c}}
$$

Proof of proposition 2: We can now prove proposition 2. With two instruments, consumption subsidies $s_{c}$ and entry subsidies $s$, the government budget constraint is given by $t \cdot L=s \cdot M^{E}+s_{c} \cdot M \cdot \bar{r}$. Using (A2), (A3) and $M \cdot \bar{r}=\beta L /\left(1-s_{c}\right)$ this can be rewritten as

$$
t=\frac{\beta\left(\sigma k f_{e} s_{c}-s+\sigma s\left(1-k s_{c}\right)\right)}{\sigma k\left(1-s_{c}\right)\left(f_{e}-s\right)}
$$

Government maximizes welfare, which using $P=\left(1-s_{c}\right)^{\frac{\sigma}{\sigma-1}}(\beta L / \sigma f)^{\frac{1}{1-\sigma}}\left(1 / \rho \varphi^{*}\right)$ reads as

$$
W=L[1-t-\beta \cdot \ln (P)+\beta(\ln \beta-1)]=L\left[1-t+\beta \cdot \ln \left(\varphi^{*}\right)-\frac{\beta \sigma}{(\sigma-1)} \cdot \ln \left(1-s_{c}\right)+\frac{\beta}{(\sigma-1)} \cdot \ln (L)+b\right] \text {. }
$$

Using (A2) and (A4), and taking first-order conditions with respect to $s$ and $s_{c}$, we obtain

$$
\frac{d W}{d s_{c}}=\frac{\beta\left(\sigma k f_{e}\left(1-\sigma s_{c}\right)-s\left(1+\sigma\left(\sigma+k-2-\sigma k s_{c}\right)\right)\right.}{\sigma k(\sigma-1)\left(1-s_{c}\right)^{2}\left(f_{e}-s\right)}=0, \quad \frac{d W}{d s}=\frac{\beta\left(f_{e}-\sigma\left(f_{e} s_{c}+s-s s_{c}\right)\right)}{\sigma k\left(1-s_{c}\right)\left(f_{e}-s\right)^{2}}=0
$$

The solution to this equation system is $s_{c}=1 / \sigma$ and $s=0$, as stated in proposition 2 . Substituting this into (A4) then yields the corresponding tax rate $t=\beta /(\sigma-1)$. Note that consumer prices are now given by $p_{c}(\varphi)=\left(1-\frac{1}{\sigma}\right) / \rho \varphi=1 / \varphi$. Hence, consumers pay prices equal to marginal costs. As there are no further (net) distortions except for the monopolistic mark-up pricing (see above), this policy where government subsidizes manufacturing consumption instead of firm entry, thus, achieves the first-best allocation. 


\section{Appendix B: The open economy equilibrium}

Proof of Lemma 1: We have $\gamma_{i} L_{i}=M_{i} \cdot \bar{r}_{i}+t_{i} L_{i}$, where $\bar{r}_{i}=r_{i}\left(\tilde{\varphi}_{i}\right)+p_{x i} r_{x i}\left(\tilde{\varphi}_{x i}\right)$, which states that aggregate earnings in manufacturing come from government spending and the revenue of manufacturing firms. Hence, $M_{i}=\left(\gamma_{i}-t_{i}\right) L_{i} / \bar{r}_{i}$ for $i=H, F$. Substituting these terms into (11), using the analogous trade balance for country $F$ and $\lambda \equiv L_{F} / L_{H}$, we obtain

$$
\frac{\gamma_{H}-t_{H}}{1+b_{H}}=\frac{\lambda\left(\gamma_{F}-t_{F}\right)}{1+b_{F}}+\gamma_{H}-\beta-t_{H} \quad \frac{\gamma_{F}-t_{F}}{1+b_{F}}=\frac{\gamma_{H}-t_{H}}{\lambda\left(1+b_{H}\right)}+\gamma_{F}-\beta-t_{F}
$$

where

$$
\begin{aligned}
& b_{H}=\frac{r_{H}\left(\tilde{\varphi}_{H}\right)}{p_{x H} \cdot r_{x H}\left(\tilde{\varphi}_{x H}\right)}=\frac{\tau^{\sigma-1}}{p_{x H}}\left(\frac{\tilde{\varphi}_{H}}{\varphi_{H}^{*}} \frac{\varphi_{F}^{*}}{\tilde{\varphi}_{x H}}\right)^{\sigma-1}=\frac{1}{\phi}\left(\frac{\varphi_{F}^{*}}{\varphi_{H} *}\right)^{k}=\frac{1}{\phi}\left(\frac{\zeta \chi-\phi}{1-\phi \zeta \chi}\right) \\
& b_{F}=\frac{r_{F}\left(\tilde{\varphi}_{F}\right)}{p_{x F} \cdot r_{x F}\left(\tilde{\varphi}_{x F}\right)}=\frac{\tau^{\sigma-1}}{p_{x F}}\left(\frac{\tilde{\varphi}_{F}}{\varphi_{F}^{*}} \frac{\varphi_{H}^{*}}{\tilde{\varphi}_{x F}}\right)^{\sigma-1}=\frac{1}{\phi}\left(\frac{\varphi_{F}^{*}}{\varphi_{H}^{*}}\right)^{k}=\frac{1}{\phi}\left(\frac{1-\phi \zeta \chi}{\zeta \chi-\phi}\right)
\end{aligned}
$$

Solving (B1) for $\gamma_{i}$ yields

$$
\gamma_{H}=\beta \cdot \frac{\left(1+b_{H}\right)\left(\lambda-b_{F}\right)}{1-b_{H} b_{F}}+t_{H} \quad \gamma_{F}=\beta \cdot \frac{\left(1+b_{F}\right)\left(\frac{1}{\lambda}-b_{H}\right)}{1-b_{H} b_{F}}+t_{F}
$$

Plugging in the expressions for $b_{H}$ and $b_{H}$ then yields $\gamma_{H}$ and $\gamma_{F}$ as given in lemma 1.

Parameter restrictions to ensure $0<\gamma_{i}<1$ for $i=H, F$ : We firstly impose restrictions to ensure that $0<\beta_{i} \equiv \gamma_{i}-t_{i}<1$ for $i=H, F$. Assuming without loss of generality that country $F$ lags behind country $H$ in terms of size and/or effective sunk entry costs and/or technology, we have $0<\imath \leq 1$ for $\imath=\{\phi, \lambda, \varsigma, \chi\}$. We then need to impose the following conditions:

$$
0<\phi<\phi_{\max } \equiv \frac{1+\lambda-\varsigma \sqrt{(1+\lambda)^{2} / \varsigma^{2} \chi^{2}-4 \lambda}}{2 \varsigma \chi}, \quad 0<\beta<\beta_{\max } \equiv \frac{(1-\phi \zeta \chi)(\zeta \chi-\phi)}{\zeta \chi\left(\phi \zeta \chi(1+\lambda)-\lambda \phi^{2}-1\right)}
$$

If the conditions in (B3) hold we have $0<\beta_{F}<\beta_{H}<1$, with $\partial \beta_{H} / \partial \imath<0$ and $\partial \beta_{F} / \partial \imath>0$ for $\imath=\{\lambda, \varsigma, \chi\}$ and $\partial \beta_{H} / \partial \phi>0, \quad \partial \beta_{H} / \partial \phi<0$. We then need to assume $t_{i}<\gamma_{i}$ and $\left|t_{F}-t_{H}\right|<\left|\gamma_{H}-\gamma_{F}\right|$ so that results for $\beta_{i}$ carry over to $\gamma_{i}$. In words, (B3) requires that country asymmetries are small relative to trade openness, and that per-capita manufacturing expenditure $\beta$ and tax rates $t_{i}$ are sufficiently small. Under these conditions the leading country $H$ is specialized in manufacturing, and trade integration reinforces this pattern.

Equilibrium firm masses: Using (10) and (12) we obtain the following expressions

$$
\begin{aligned}
& M_{H}=\frac{\left(\gamma_{H}-t_{H}\right) L_{H}}{\sigma\left(\bar{\pi}_{H}+f+p_{x H} \cdot f_{x}\right)}=\frac{(k+1-\sigma) \beta L_{H}}{\sigma k f} \cdot \frac{\left(1+\phi^{2} \lambda-(1+\lambda) \phi \zeta \chi\right)}{\left(1-\phi^{2}\right)(1-\phi \zeta \chi)} \\
& M_{F}=\frac{\left(\gamma_{F}-t_{F}\right) L_{F}}{\sigma\left(\bar{\pi}_{F}+f+p_{x F} \cdot f_{x}\right)}=\frac{(k+1-\sigma) \beta L_{F}}{\sigma k f} \cdot \frac{\left(\zeta \chi\left(\lambda+\phi^{2}\right)-\phi(1+\lambda)\right)}{\lambda\left(1-\phi^{2}\right)(\zeta \chi-\phi)} \\
& M_{H}^{E}=\frac{\delta M_{H}}{\left(\varphi_{H}^{\min } / \varphi_{H}^{*}\right)^{k}}=\frac{(\sigma-1) \beta L_{H}}{\sigma k\left(f_{e}-s_{H}\right)} \cdot \frac{\zeta \chi\left(1+\phi^{2} \lambda-\phi \zeta \chi(1+\lambda)\right)}{(\zeta \chi-\phi)(1-\phi \zeta \chi)}
\end{aligned}
$$




$$
\begin{aligned}
& M_{F}^{E}=\frac{\delta M_{F}}{\left(\varphi_{F}^{\min } / \varphi_{F}^{*}\right)^{k}}=\frac{(\sigma-1) \beta L_{F}}{\sigma k\left(f_{e}-s_{F}\right)} \cdot \frac{\left(\zeta \chi\left(\lambda+\phi^{2}\right)-\phi(1+\lambda)\right)}{\lambda(\zeta \chi-\phi)(1-\phi \zeta \chi)}, \\
& M_{x H}=\left(\frac{\varphi_{H}^{*}}{\Lambda \varphi_{F}^{*}}\right)^{k} M_{H}=\frac{(k+1-\sigma) \beta L_{H}}{\sigma k f_{x}} \cdot \frac{\phi\left(1+\phi^{2} \lambda-\phi \zeta \chi(1+\lambda)\right)}{\left(1-\phi^{2}\right)(\zeta \chi-\phi)} \\
& M_{x F}=\left(\frac{\varphi_{F}^{*}}{\Lambda \varphi_{H}^{*}}\right)^{k} M_{F}=\frac{(k+1-\sigma) \beta L_{F}}{\sigma k f_{x}} \cdot \frac{\phi\left(\zeta \chi\left(\lambda+\phi^{2}\right)-\phi(1+\lambda)\right)}{\lambda\left(1-\phi^{2}\right)(1-\phi \zeta \chi)}
\end{aligned}
$$

The mass of firms active in country $i \quad M_{t i}=M_{i}+M_{x j}$ (i.e., consumption variety) is then readily obtained. From these expressions it follows that

$$
\begin{aligned}
& \frac{M_{H}}{M_{F}}=\frac{L_{H} \lambda(\zeta \chi-\phi)\left(1+\phi^{2} \lambda-\phi \zeta \chi(1+\lambda)\right)}{L_{F}(1-\phi \zeta \chi)\left(\zeta \chi\left(\lambda+\phi^{2}\right)-\phi(1+\lambda)\right)}>1 \\
& \frac{M_{H}^{E}}{M_{F}^{E}}=\frac{L_{H}\left(f_{e}-s_{F}\right) \lambda \zeta \chi\left(1+\lambda \phi^{2}-\phi \zeta \chi(1+\lambda)\right)}{L_{F}\left(f_{e}-s_{H}\right)\left(\zeta \chi\left(\lambda+\phi^{2}\right)-\phi(1+\lambda)\right)}>1 \\
& \frac{M_{t H}}{M_{t F}}=\frac{(\zeta \chi-\phi)\left[L_{H} \lambda f_{x}\left(1+\phi^{2} \lambda-\phi \zeta \chi(1+\lambda)\right)+\phi L_{F} f\left(\zeta \chi\left(\lambda+\phi^{2}\right)-\phi(1+\lambda)\right)\right]}{(1-\phi \zeta \chi)\left[\phi L_{H} \lambda f\left(1+\phi^{2} \lambda-\phi \zeta \chi(1+\lambda)\right)+L_{F} f_{x}\left(\zeta \chi\left(\lambda+\phi^{2}\right)-\phi(1+\lambda)\right)\right]}>1
\end{aligned}
$$

as $0<\lambda \leq 1, \quad 0<\chi \leq 1, \quad 0<\varsigma \leq 1, \quad L_{H} \geq L_{F}>0, \quad 0<\left(f_{e}-s_{H}\right) \leq\left(f_{e}-s_{F}\right)$ and $f_{x}>f>0$ imply $(\zeta \chi-\phi)>(1-\phi \zeta \chi)$ and $\lambda \zeta \chi\left(1+\phi^{2} \lambda-\phi \zeta \chi(1+\lambda)\right)>\left(\zeta \chi\left(\lambda+\phi^{2}\right)-\phi(1+\lambda)\right)$. That is, the leading country has more entrants, surviving firms and consumption variety. As the leading cutoff productivity is also higher (or at most equal) in the leading country welfare must therefore be higher.

Symmetrical open economy case: With $\lambda=\varsigma=\chi=1$, eqs. (B4)-(B6) simplify to the following expressions in the symmetrical case

$$
\begin{array}{lrl}
M^{E}=\frac{(\sigma-1) \beta L}{\sigma k\left(f_{e}-s\right)}=M_{\text {aut }}^{E}, & M=\frac{(k+1-\sigma) \beta L}{\sigma k f} \cdot \frac{1}{1+\phi}<M_{\text {aut }} \\
M_{x}=\frac{(k+1-\sigma) \beta L}{\sigma k f_{x}} \cdot \frac{\phi}{1+\phi} & \rightarrow M_{t}=\frac{(k+1-\sigma) \beta L}{\sigma k f} \cdot \frac{1+\frac{f}{f_{x}} \phi}{1+\phi}<M_{\text {aut }}
\end{array}
$$

These expressions show that the move from autarky to trade among symmetrical countries causes exit of domestic firms but per se does not affect the mass of entrants under the Paretodistribution. Our assumption $f_{x}>f$ implies that the move from autarky to trade causes a reduction of consumption diversity with symmetrical countries (also see Baldwin 2005 on this). However, the introduction of trade still implies a welfare gain for both countries as $\varphi^{*}>\varphi_{\text {aut }}^{*}$ in the symmetrical case. 


\section{Appendix C: Consumption subsidies in the open economy}

Preliminaries: Consider ad-valorem subsidies to consumption of manufacturing varieties, where domestic and imported varieties are subsidized with the same rate $s_{c i}$ in country $i$. The aggregate value of manufacturing consumption in country $i$ can be written as $C_{i} \equiv M_{i} \cdot r_{i}\left(\tilde{\varphi}_{i}\right)+M_{j} \cdot p_{x j} \cdot r_{x j}\left(\tilde{\varphi}_{x j}\right)$. In equilibrium we must have $\beta L_{i}=\left(1-S_{c i}\right) C_{i}$. The government budget constraint, $t_{i} L_{i}=s_{c i} C_{i}$ thus implies

$$
t_{i}=\left(\beta \cdot s_{c i}\right) /\left(1-s_{c i}\right)
$$

Furthermore, the CES price level in the open economy is $P_{i}=\left(1-s_{c i}\right) M_{t i}^{1 /(1-\sigma)} /\left(\rho \cdot \tilde{\varphi}_{t i}\right)$. Taking into account that $r_{i}\left(\tilde{\varphi}_{t i}\right)=\left(1-s_{c i}\right)^{-\sigma}\left(P_{i} \rho \tilde{\varphi}_{t i}\right)^{\sigma-1} \beta L_{i}$, and substituting in $P_{i}$ we thus have $M_{t i}=\beta L_{i} /\left(\left(1-s_{c i}\right)^{\sigma} \cdot r_{i}\left(\tilde{\varphi}_{t i}\right)\right)$. Using the replacement $r_{i}\left(\tilde{\varphi}_{t i}\right)=\left(\tilde{\varphi}_{t i} / \varphi_{i}{ }^{*}\right)^{\sigma-1} \sigma f$, we can then write $M_{t i}=\left(1-S_{c i}\right)^{-\sigma}\left(\beta L_{i} / \sigma f\right)\left(\tilde{\varphi}_{t i} / \varphi_{i}^{*}\right)^{1-\sigma}$ and the CES price level becomes

$$
P_{i}=\left(1-S_{c i}\right)^{\frac{\sigma}{\sigma-1}} \cdot\left(\frac{\beta L_{i}}{\sigma f}\right)^{\frac{1}{1-\sigma}} \cdot \frac{1}{\rho \cdot \varphi_{i}^{*}}
$$

Note that cutoffs $\varphi_{i}^{*}$ are not affected by consumption subsidies as (FEC) and (ZCPC) do not change. The cutoffs are given as in (10) with $\tilde{f}_{e}=f_{e}$ since we neglect entry subsidies in this appendix.

Optimal consumption subsidy: Welfare in country $i$ is $W_{i}=L_{i}\left[1-t_{i}-\beta \ln P_{i}+\beta(\ln \beta-1)\right]$. Substituting in (C1) and (C2) and taking first-order conditions with respect to $s_{c i}$ we obtain

$$
\frac{d W_{i}}{d s_{c i}}=-\frac{d t_{i}}{d s_{c i}}-\beta \frac{1}{P_{i}} \frac{d P_{i}}{d s_{c i}}=-\frac{\beta}{\left(1-s_{c i}\right)^{2}}+\frac{\sigma}{\sigma-1} \frac{\beta}{\left(1-s_{c i}\right)}=0
$$

Solving (C3) immediately leads to $s_{c i}=1 / \sigma$. Furthermore, the consumption subsidy of the other country, $s_{c j}$, does not affect welfare in country $i$. There is thus no difference between the Nash- and the cooperative consumption subsidy in this two-region economy. Hence, this policy scheme of subsidizing manufacturing consumption is equivalent to the autarky case and leads again to the first-best allocation. 


\section{Appendix D: Data}

List of countries included in the empirical analysis $(\mathrm{N}=81)$ : Argentina, Armenia, Australia, Austria, Belgium, Bolivia, Brazil, Bulgaria, Burkina Faso, Canada, Chile, China, Colombia, Croatia, Czech Republic, Denmark, Dominican Republic, Ecuador, Egypt, Arab Rep., Finland, France, Georgia, Germany, Ghana, Greece, Hong Kong, Hungary, India, Indonesia, Ireland, Israel, Italy, Jamaica, Japan, Jordan, Kazakhstan, Kenya, Korea, Rep, Kyrgyz Republic, Latvia, Lebanon, Lithuania, Madagascar, Malawi, Malaysia, Mexico, Morocco, Mozambique, Netherlands, New Zealand, Nigeria, Norway, Pakistan, Panama, Peru, Philippines, Poland, Portugal, Romania, Russian Federation, Senegal, Singapore, Slovak Republic, Slovenia, South Africa, Spain, Sri Lanka, Sweden, Switzerland, Tanzania, Thailand, Tunisia, Turkey, Uganda, Ukraine, United Kingdom, United States, Uruguay, Venezuela, Zambia, Zimbabwe.

Data sources:

$\begin{array}{ll}\tilde{f}_{e, i} & \begin{array}{l}\text { Cost+time measure provided in Djankov et al. (2002), Table III, measured as } \\ \text { \% of country GDP per capita in US-\$ for 1999. We lose } 4 \text { observations (Mali, } \\ \text { Mongolia, Taiwan and Vietnam) due to a lack of trade openness data }\end{array} \\ \text { OPEN }_{i} & \begin{array}{l}\text { Squalli and Wilson (2006), Table 2. CTI- and TI-based trade openness } \\ \text { measures for the year 2000 using Penn World Tables data }\end{array} \\ \text { Population }_{i} & \begin{array}{l}\text { Total population size (in 1,000) for 1999, World Bank, World Development } \\ \text { Indicators }\end{array} \\ \text { Employment }_{i} & \begin{array}{l}\text { Total employment level for 1999 (in 1,000), International Labour Office (ILO), } \\ \text { LABORSTA - data base for labour statistics }\end{array}\end{array}$





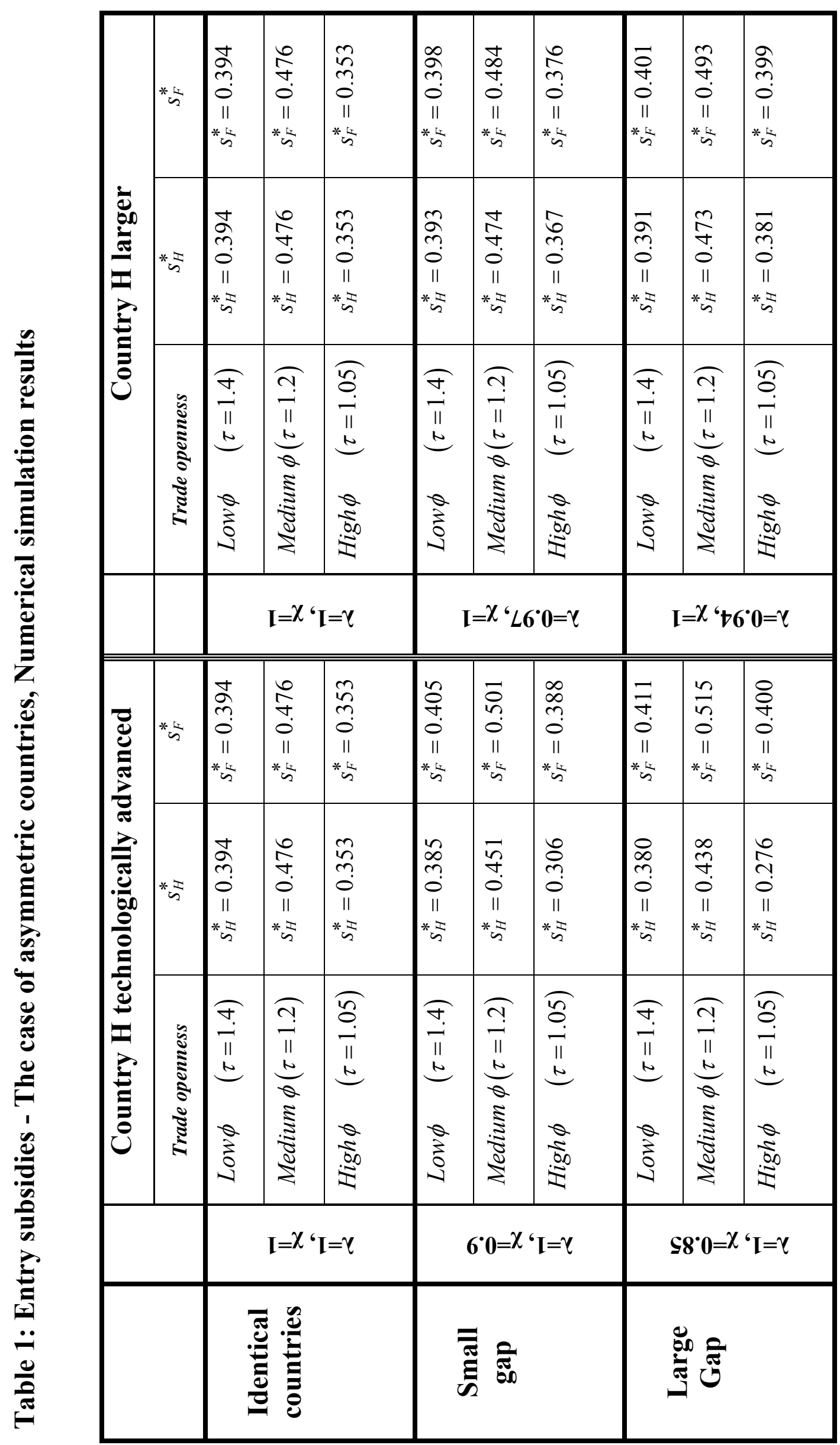

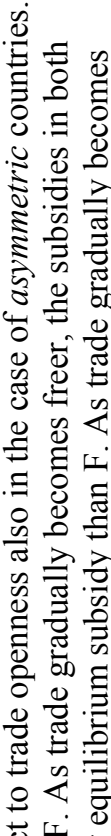

II

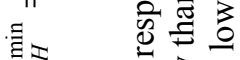

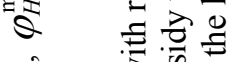
○

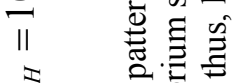
늘 N 究 11 일 4 茜完告 iो त

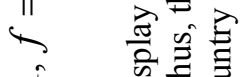
ㅁ. त औे II $\Xi \Xi \Xi$

$\dot{0}$ i ○ छ छ छ 0 ป d

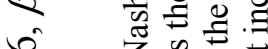
II Z b I $\infty$ 焉焉

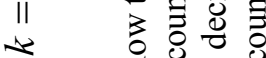

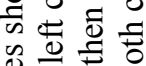
월 สี ชे के

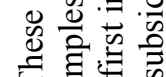

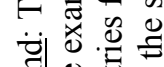

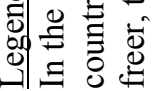
$\pi$ 


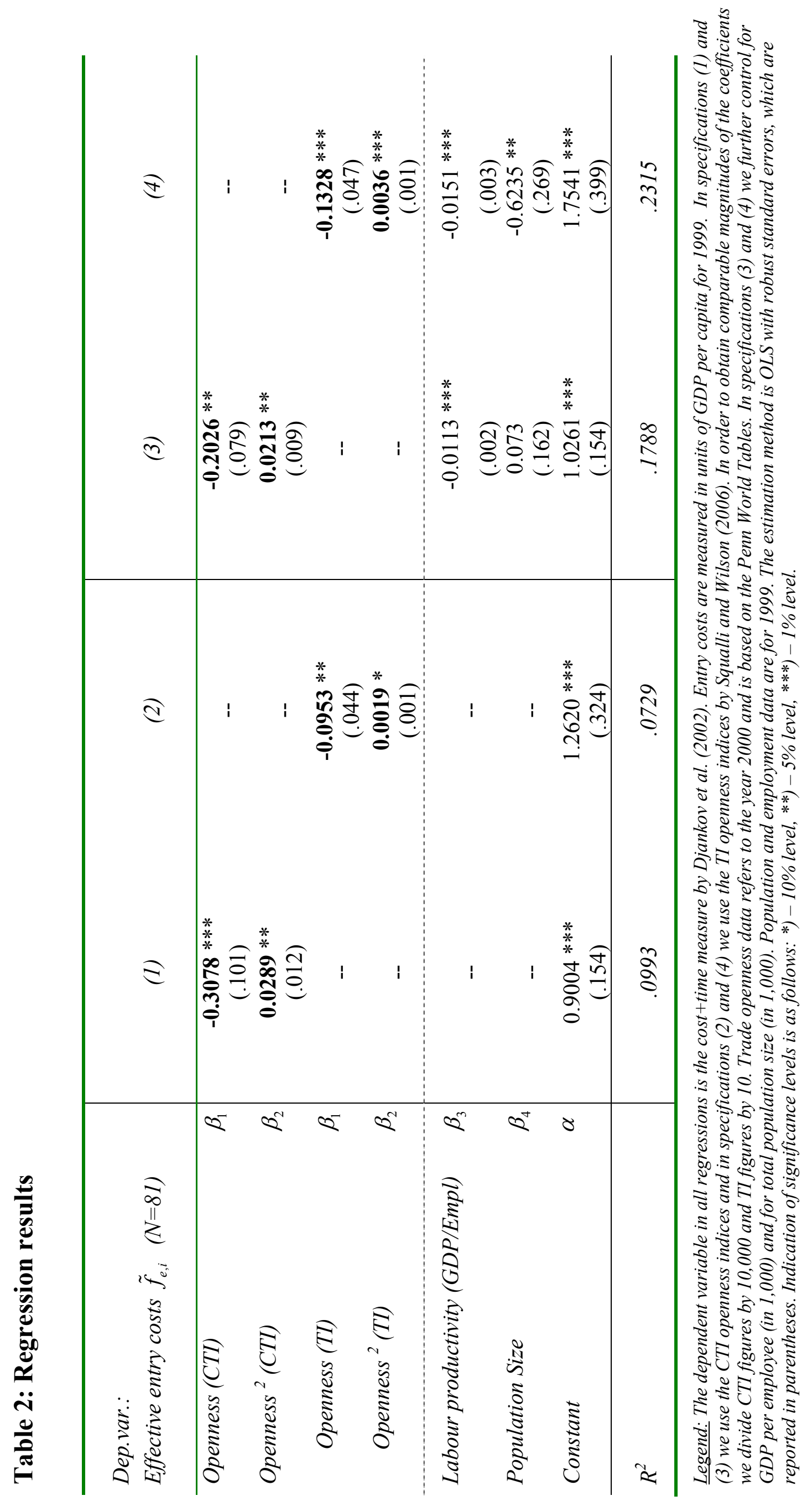

